\title{
Risky recombinations: Institutional gatekeeping in the innovation process
}

\author{
John-Paul Ferguson \\ Stanford University \\ jpferg@stanford.edu
}

\author{
Gianluca Carnabuci \\ European School of Management and Technology \\ gianluca.carnabuci@esmt.org
}

Forthcoming; manuscript accepted at Organization Science, 2 November 2016

\begin{abstract}
Theories of innovation and technical change posit that inventions that combine knowledge across technology domains have greater impact than inventions drawn from a single domain. The evidence for this claim comes mostly from research on patented inventions and ignores failed patent applications. We draw on insights from research into institutional gatekeeping to theorize that, to be granted, patent applications that span technological domains must have higher quality than otherwise-comparable, narrower applications. Using data on failed and successful patent applications, we estimate an integrated, two-stage model that accounts for this differential selection. We find that more domain-spanning patent applications are less likely to be approved, and that controlling for this differential selection reduces the estimated effect of knowledge recombination on innovative impact by about half. By conceptualizing the patentapproval process as a form of institutional gatekeeping, this paper highlights the institutional underpinnings of and constraints on the innovation process.
\end{abstract}

\section{Introduction}

Innovation scholarship has found that inventions have more impact when they combine knowledge across technological boundaries than when they draw from a single technology domain (Rosenkopf \& Nerkar 2001, Nerkar 2003, Sorenson \& Fleming 2004, Miller, Fern \& Cardinal 2007, Carnabuci \& Bruggeman 2009, Carnabuci \& Operti 2013). The reason is that technological knowledge develops in a cumulative, path-dependent fashion (Dosi 1982, Nerkar 2003), resulting in well-circumscribed knowledge domains (Carnabuci \& Bruggeman 2009). Consequently, spanning knowledge domains can give an inventor a better vision of technological possibilities, such that the ideas they choose to incorporate in inventions will be, on average, of higher quality (Hargadon \& Sutton 1997, Hargadon 2002). This argument has produced significant insight into the determinants of innovation and has spawned a fertile line of organizational and strategy research (e.g., Burt (2004); Hargadon \& Sutton (1997); Rosenkopf \& Nerkar (2001)). 
In addition to being theoretically fruitful, the knowledge-recombination argument has received substantial empirical support from diverse economic and technological contexts across multiple levels of analysis (see Carnabuci (2014) for a recent review). Most such studies use large-scale patent data to show that the greater the recombinant breadth of an invention-i.e., the larger the set of technology domains from which it combines knowledge - the greater its impact on future technological developments tends to be (Rosenkopf \& Nerkar 2001, Sorenson \& Fleming 2004, Miller, Fern \& Cardinal 2007, Yayavaram \& Ahuja 2008, Carnabuci \& Operti 2013).

The knowledge-recombination literature gives theoretical insight into the determinants of inventions' impact. However, critics have lamented that most studies treat the notion of knowledge recombination in abstract or metaphorical terms, obscuring the concrete institutional reality within which innovation processes unfold (e.g., Carnabuci \& Operti (2013, pp. 1591-1592). Most notably, prior research has neglected the role that patent offices play in selecting which inventions become patented and which do not.

We argue that examining the role of patent offices is useful, for practical and theoretical reasons. Practically, patent offices are responsible for organizing, and have jurisdiction over, the patent-approval process. Contrary to arguments that the approval process is trivial because patent offices approve virtually any application (Lemley \& Sampat 2008), a growing number of studies have shown that the failure rates for patent applications are much higher than earlier work assumed (Bessen 2003, Harhoff \& Reitzig 2004, Harhoff \& Wagner 2009, von Graevenitz, Wagner \& Harhoff 2011, Carley, Hegde \& Marco 2015). Theoretically, examining the role of patent offices is important because they act as "institutional gatekeepers," influencing a crucial, albeit often neglected, stage of the innovation process (Clayman \& Reisner 1998). By selecting which patents to grant, patent offices influence which inventions enter the stock of public knowledge upon which innovators draw (Fleming 2001, Carnabuci \& Bruggeman 2009). In a knowledge-based economy, where the publicly available technological knowledge codified within patents is a prime source of knowledge spillover, technological progress, and economic growth (Mokyr 2002, Foray 2006), illuminating the gatekeeping role of patent offices is central to a deeper, institutionally informed understanding of innovation.

This study develops and tests a novel process model that explicitly accounts for the gatekeeping role of patent offices during the approval process. We integrate extant theory on the link between 
knowledge recombination and innovation with insights from the literature on institutional gatekeepers (Zuckerman 1999, Coffee Jr 2006, Andrews \& Caren 2010, Hsu \& Elsbach 2012, Short, Toffel \& Hugill 2013). Prior innovation research pointed out two explanations for the positive association between knowledge recombination and innovation impact. One is based on how familiar or typical a combination is, and is often conceived of in terms of mean and variance effects (e.g., Fleming (2001), Uzzi, Mukherjee, Stringer \& Jones (2013)). The other focuses on the cross-sectional breadth of a combination, independently of how frequently the combination has been observed before, and is conceived of in terms of mean effects (e.g., Lerner (1994)). In this paper, we concentrate on the latter, for two reasons. First, the positive association between recombinant breadth ${ }^{1}$ and citation impact is one of the most frequently replicated findings in innovation research (Lerner 1994, Fleming \& Sorenson 2001, Fleming 2001, Nerkar 2003, Sorenson \& Fleming 2004, Sorenson, Rivkin \& Fleming 2006, Sampson 2007, Fleming, Mingo \& Chen 2007, Huang \& Chen 2010, Srivastava \& Gnyawali 2011, Schilling \& Green 2011, Sterzi 2013, Gruber, Harhoff \& Hoisl 2013, Kim, Arthurs, Sahaym \& Cullen 2013, Corredoira \& Banerjee 2014, Wang, Rodan, Fruin \& Xu 2014, Hsu \& Lim 2014, Kaplan \& Vakili 2015, Carnabuci \& Operti 2015, Jaffe \& de Rassenfosse 2016). Second, the concept of recombinant breadth offers a clear opportunity for theoretical integration between the innovation and gatekeeping perspectives.

We define institutional gatekeepers as those market institutions that filter "the flow of goods and ideas through the society" by imposing standards "that function as selection criteria" (Clayman \& Reisner 1998, p. 179). We draw upon research suggesting that gatekeepers find it hard to understand, and therefore inadvertently sanction, boundary-spanning goods and ideas when trying to assess whether they meet their selection criteria (Zuckerman 1999, Zuckerman 2004, Leahey 2007, Hsu, Hannan \& Koçak 2009, Ruef \& Patterson 2009). We theorize that patent offices may systematically undervalue inventions that span technological boundaries, relative to those that do not. Consequently, we predict that boundary-spanning inventions should be more likely to fail the patent-approval process. Said otherwise, boundary-spanning patent applications will only be granted if they are of higher quality than otherwise-comparable, narrower applications.

To test our theoretical arguments, we examine detailed information on both granted and non-

\footnotetext{
${ }^{1}$ In this article, when we refer to "knowledge recombination," we are referring to recombinant breadth unless we specify otherwise.
} 
granted patents within the European Patent Office between 1983 and 2007. Like most prior work, we find that recombinant breadth is associated with a larger citation impact. However, we also find that recombinant breadth is associated with a significantly lower likelihood of application approval. In a two-stage selection model, we compare the effect of breadth on citation impact when ignoring and controlling for differential selection, and find that the estimate of patent impact is substantially overstated in the former case. An implication of our findings is that studies that ignore the patentapproval process, and the differential selection applied in that process to patent applications that combine many technology domains, will overstate the contribution of knowledge recombination to future innovation.

Our findings do not and are not meant to undermine the idea that drawing upon knowledge across technological boundaries can produce more impactful patents. Rather, our goal is to contribute new insights into the mechanisms driving innovation by developing an explanation of the link between knowledge recombination and innovation impact that accounts for the institutional gatekeeping role of patent offices.

\section{Theoretical background}

Institutional gatekeepers are organized institutions whose objective and jurisdiction is to filter, by enforcing specific selection criteria, the flow of goods and information reaching the market (Clayman \& Reisner 1998, p. 179). Examples include accreditation agencies, such as AACSB and AMBA, that certify which business schools and programs have met quality standards; funding agencies, such as the NSF, which distribute research support based on competitive grant proposals; and governmental agencies like the U.S. Food and Drug Administration. By attesting which products or services satisfy predefined evaluation criteria and required quality standards, gatekeepers act as "legitimating agencies" (Durand \& McGuire 2005, Sine, David \& Mitsuhashi 2007) that funnel the set of goods and information reaching the greater public. Because their choices directly affect the workings of markets (Polidoro 2013), gatekeeping institutions typically strive to show that their evaluation criteria and processes are "objective." Nevertheless gatekeeping institutions can deviate from objectivity in several ways (Clayman \& Reisner 1998, Short, Toffel \& Hugill 2013, Boudreau, Guinan, Lakhani \& Riedl 2013, Webster, Jensen \& Palangkaray 2014). 
A relevant deviation here involves how categorical structures influence evaluators. Gatekeepers tend to use well-established, taken-for-granted categorical boundaries as cognitive and organizational shortcuts (Zuckerman 2003, Hannan, Pólos \& Carroll 2007) when evaluating candidates. When the goods or services being evaluated span those boundaries, they incur an illegitimacy discount in the eyes of gatekeepers (Zuckerman 1999). For example, funding agencies tend to evaluate less positively and systematically underfund scientific research proposals that span established disciplinary boundaries (Porter \& Rossini 1985). Boudreau et al. (2013) find in randomized experiments that such discounting stems from combining knowledge across the "limits of [evaluators'] own knowledge and, more particularly, the bounds of the established map of science" (p. 27). Furthermore, this discounting effect holds net of grant-application quality. Such results suggest that the gatekeeping institutions responsible for funding science tend to place higher quality requirements on boundary-spanning grant applications than on narrower ones.

Applied to patent offices, these findings suggest that the link between recombinant breadth and technological innovation may be more complex than extant innovation research portrays it to be. Innovation scholars argue that combining knowledge across technological boundaries increases the likelihood of developing impactful, breakthrough inventions (Tushman 1977, Tushman \& Scanlan 1981, Hargadon \& Sutton 1997, Rosenkopf \& Nerkar 2001, Carnabuci \& Operti 2013). Consistent with this view, multiple studies using patent data show that inventions spanning broader sets of technology domains have more impact on future technological developments. However, this research has focused on granted patents, ignoring the gatekeeping role of patent offices. A more institutionally informed perspective on the patenting process would suggest that while more recombinant inventions may have greater impact, their tendency to draw upon knowledge from multiple technology domains may make them harder objects for such gatekeepers to evaluate and certify. This may have negative implications for the approval rate of patent applications associated with such inventions.

\section{An integrated model}

Innovation research and gatekeeping research point to different causal mechanisms through which knowledge recombination affects innovation. We begin by noting that these mechanisms operate at different and logically subsequent points in the innovation process. When we talk about patent 


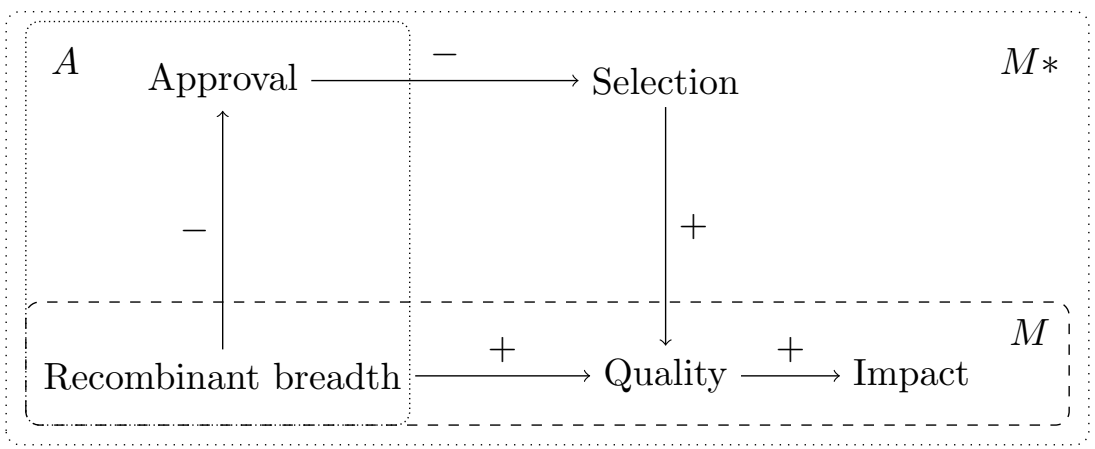

Figure 1: Theorized relationship between recombinant breadth and innovation impact. Recombination increases quality, which in turn improves impact $(M)$. But it also reduces approval $(A)$, which subjects recombinants to stronger selection and thus raises observed quality. Thus the impact benefits when approval is not taken into account $(M *)$ can be overstated.

impact, we presume that the invention has been patented. When we talk about patent approval, that presumption is what is problematized. Assuming away either of these stages only makes sense if the decision-making processes of the relevant actors in each stage would tend to yield the same results. Because the innovation and institutional-gatekeeping literatures suggest opposite effects, we should explicitly theorize both.

Figure 1 sketches our proposed integration. The bottom row shows the link between recombinant breadth and impact as theorized in most work on innovation. The relationship between recombinant breadth and impact, denoted $M$, is positive. The left column shows the effect of recombinant breadth on patent approval. We postulate that inventions that draw knowledge from distinct technological domains have a lower likelihood of patent approval; we label this effect $A$.

An empirical implication of this model is that differential selection will ensue. Stricter approval criteria will subject boundary-spanning patent applications to stronger selection, raising the quality bar they have to clear to be granted patent. Differential selection can produce a positive correlation between recombinant breadth and impact among granted patents even if breadth does not increase invention quality. Both $M$ and $A$ will independently engender a correlation between recombinant breadth and impact in the population of granted patents. We can define $M *$ as the effect of breadth on impact when examining granted patents. Because $M *$ does not control for selection, it conflates $M$ and $A$. Thus the benefits of breadth on impact can be overstated when one examines only granted patents.

Our unification suggests four possible population-level outcomes produced by the relationships 
shown in figure 1, depending on whether neither, either, or both effects are at work. To describe them, we introduce some notation. Assume that we have two classes of patent applications, narrow (applications that fall within a single technology domain) and broad (applications combining knowledge across technological boundaries). Patent applications vary in their quality, $q$, which is unobserved. The two classes have quality distributions with means $\mu_{n}$ and $\mu_{b}$. Assume that impact $m$ increases with application quality: $m \uparrow q$. The probability of an application's being approved $a$ similarly increases with quality: $a \uparrow q$. We can then define $M$ as the difference in mean quality between broad and narrow patents $\left(\mu_{b}-\mu_{n}\right)$ and $A$ as the difference in the probability that an application is approved, conditional on its being narrow or broad $(a|b-a| n)$. Examiners apply some quality threshold $t$ to patent applications and grant patent when $q>t$. Thus we can define the mean quality of granted narrow and broad patents as $\mu_{n}^{*}$ and $\mu_{b}^{*} ; \mu_{n}^{*}>\mu_{n}$ and $\mu_{b}^{*}>\mu_{b}$ for all positive thresholds.

We represent these in figure 2. In panel I, we picture a baseline world where knowledge recombination has no effect on anything. In this case $M=A=0$ and $M *=M$. Here, ignoring selection introduces no bias in the estimation of $M$. In Panel II, broader knowledge recombinations improve impact via increasing invention quality. Here, $\mu_{b}>\mu_{n}$ and therefore $M>0$. Panel II retains the assumption that knowledge recombination does not affect patent approval; thus $A=0$ and $M *=M$. Here too, ignoring $A$ does not bias estimates of $M$.

By contrast, panel III considers the effects of breadth on patent approval while assuming there are no direct effects of breadth on quality. Here $A<0$ : broad patent applications are only likely to be approved if $q>t_{b}>t_{n}$. This means that $\mu_{b}^{*}>\mu_{n}^{*}$, even though $\mu_{b}=\mu_{n}$. Therefore $M *>0$ in panel III even though $M=0$. If it is harder for broad applications to become approved then ignoring selection will upwardly bias the estimated effect of breadth on impact.

Finally, panel IV considers both effects at the same time. Overstatement of breadth benefits will still occur: $M>0$, but because $A<0, M *>M$. This also implies that the magnitude of the overstatement created by this selection bias is $\frac{\left(\mu_{b}^{*}-\mu_{n}^{*}\right)}{\left(\mu_{b}-\mu_{n}\right)}$.

Figure 2 also suggests how we would test for these effects empirically. We require an empirical strategy that estimates $M, A$, and $M *$. If recombinant breadth improves impact and poses no differential selection, as in much work on innovation, then $M>0, A=0$, and $M *=M$. If breadth complicates granting and does not help impact, as work on institutional gatekeepers suggests, then 

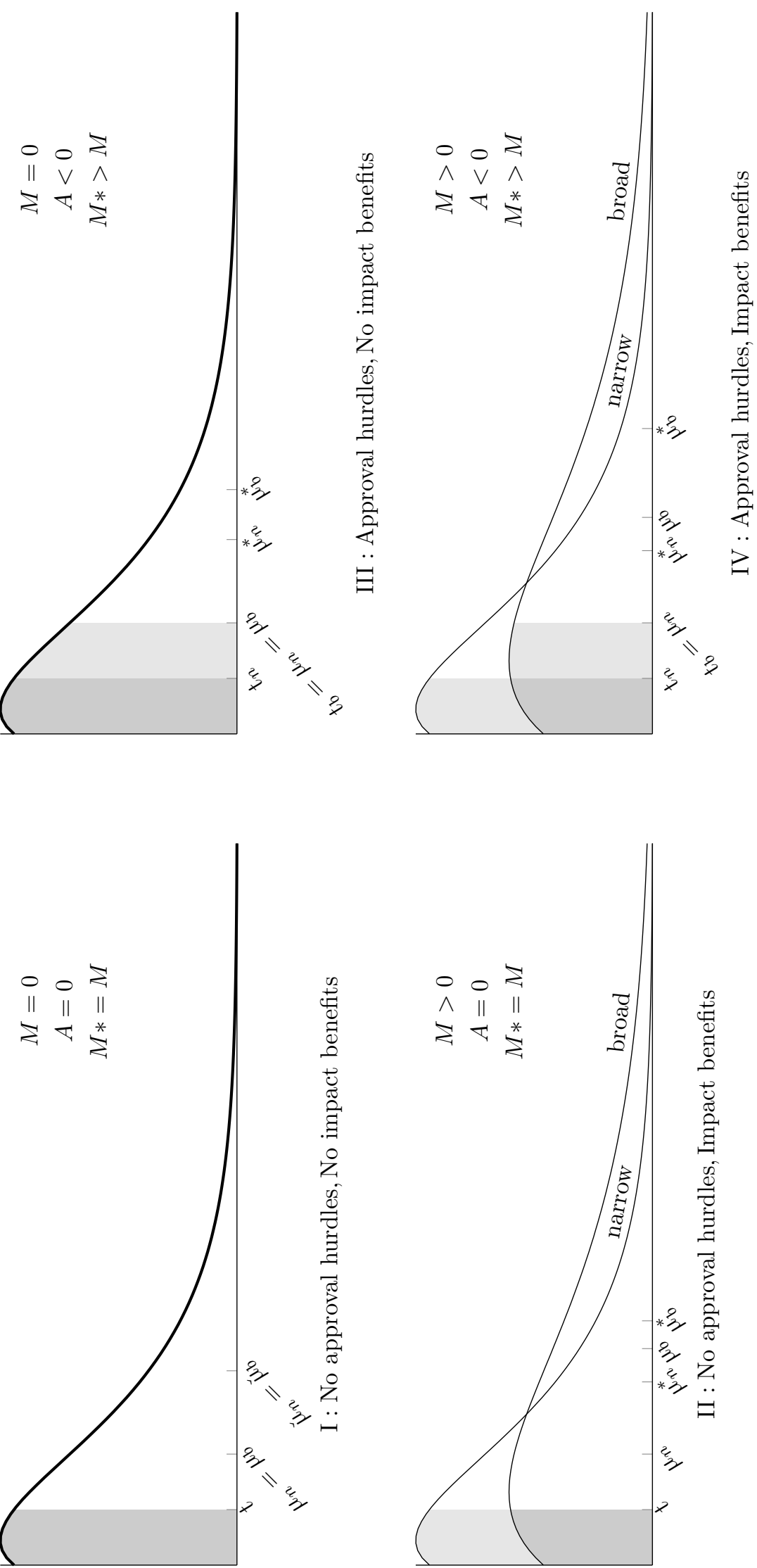

Figure 2: Theorized quality distributions and observed means for broad and narrow recombinations, under conditions of approval hurdles and/or impact benefits. Effects $M, A$, and $M *$ are described in the text. 
$M=0, A<0$, and $M *>0$. If both mechanisms are present, as we theorize, then $M>0, A<0$, and $M *>M$.

Thus, our model yields three testable hypotheses:

Hypothesis 1 Inventions that combine knowledge across technological boundaries have a lower likelihood of being granted patent.

Hypothesis 2 Inventions that combine knowledge across technological boundaries have a higher citation impact.

Hypothesis 3 Institutional gatekeeping produces differential selection among boundary-spanning inventions, such that the positive relationship between knowledge recombination and impact will be reduced when controlling for selection.

Hypothesis 2 derives from prior work; we include it here because the test for hypothesis 3 is meaningful only if there is support for hypothesis 2 .

Testing these hypotheses requires data of a specific type. We need a process in which both approval and impact are observable and can be separately modeled. The approval process should not directly affect the quality of the thing being approved. This second point is important because we theorize that approval affects impact through differential selection - that is, a different quality standard being applied - rather than through changes in quality (compare Ferguson \& Hasan (2013); see also Azoulay, Stuart \& Wang (2013) for a similar concern with status). Data on the granting and citation of patents meet these two requirements.

\section{Patent applications and patent citations}

The United States Patent and Trademark Office has long maintained detailed records of the classifications and citations of granted patent applications, but the agency did not begin publishing records of non-granted applications until 2001. Thus the standard practice in innovation research has been to use data on successful patent applications. This practice seems quite reasonable on the surface because historically the USPTO has only explicitly rejected a tiny share of all patent applications. This leads to the claim that virtually all patent applications are granted; at the extreme, Quillen \& Webster (2006) claimed that the USPTO granted patents to 97 percent of all applications (though they later revised their figure to 84 percent). Indeed it is more common to hear criticism 
of the USPTO for being a "rubber stamp" on applications (Lemley \& Sampat 2008, Carley, Hegde \& Marco 2015) than to see discussions of rejection rates.

Yet a growing body of studies have shown that few explicit rejections do not imply high granting rates. The de facto rejection rates by the USPTO and other patent authorities are far higher than the de jure rejections would imply. For example, patent examiners have several ways to encourage filers to withdraw applications that the examiners do not think will succeed (Lazaridis \& van Pottelsberghe de la Potterie 2007). The USPTO does not record such withdrawals the way it records rejections, and "Because an unknown number of unpublished applications may have been abandoned without ever being published, we can’t [sic] identify a definitive grant rate for unpublished applications" (Lemley \& Sampat 2008, p. 102). Estimates for such implicitly rejected applications by the USPTO range from 30 to 40 percent (Lemley \& Sampat 2008, Lemley \& Sampat 2012, Wegner 2006, Carley, Hegde \& Marco 2015).

Unlike its American counterpart, the European Patent Office has maintained records of both granted and failed patent applications since the 1980s. Its rates for granting, rejecting, and implicitly rejecting applications mirror the estimates given for the USPTO. Thus for example van Zeebroeck, van Pottelsberge de la Potterie \& Guellec (2009) found that while the EPO formally rejected only 4 percent of patent applications between 1980 and 1994, it granted fewer than 70 percent. More recent EPO data, including what we use here, reveal similar rates (see also Harhoff \& Wagner (2009)). Virtually all of the remaining applications were withdrawn or deemed withdrawn in the wake of the examiner's search report. In short, about one patent application in four was not approved.

These recent findings refute the assumption that failed patent applications are a negligible share of the total. However, they do not tell us whether institutional gatekeeping by the patent office has any effects on the dynamics of innovation. Research on the patent-granting process has been interested mostly in improving the efficiency of that regime from a legal or design perspective, and has been less interested in the impact of any individual patent once granted. We have hypothesized that institutional gatekeeping could systematically shape the population of granted patents. For details of the mechanisms through which this could happen in the context of the EPO, see appendix A. We turn next to the empirical data. 


\section{Method}

\section{Data sources}

Our data come from the European Patent Office, via the PATSTAT register. We focus on patents that were either granted, refused, or withdrawn. The EPO records also include information on inventors and organizations, similar to that found in USPTO data. We rely on this information as well as the recorded technological classifications and citation patterns to create our measures.

The raw EPO data contain some 1,319,630 application records with citation data. Of these, 430,256 are pending, meaning they have not yet been granted, rejected, or withdrawn. For our main analyses we focus on application records that are not pending, but we recognize that inventors can and do cite pending (and indeed rejected and withdrawn) material as well. In robustness checks we verify that analyses that include pending applications produce similar results, and we exploit the citations to failed applications to get indirect information about application quality.

Of the 848,646 non-pending applications, 844,060 have complete information on all our variables. Some records do not have complete citation data, which could bias our calculation of knowledge recombination. Others have missing data on the inventors, which could bias several of our variables. Of the complete-information records, 530,863 were approved and thus can be modeled for citation impact. For 11,387 of these, we have incomplete information on the age of their citations. ${ }^{2}$ Thus in our second stage we focus on the 519,476 granted patent applications with full data.

\section{Variables}

Dependent variables. To measure approval, we use a binary variable indicating whether an application was granted patent. We code as 1 applications which were granted and as 0 those which were rejected, withdrawn, or deemed withdrawn (Harhoff \& Wagner 2009, van Zeebroeck, van Pottelsberge de la Potterie \& Guellec 2009, Lemley \& Sampat 2012). Between 1980 and 2007, 37 percent of the closed patent applications in our data were either rejected or deemed withdrawn.

To measure impact, we count the number of citations a patent received from subsequent patents (the focal patent's forward citation count) in the five years after the patent was filed (Fleming 2001,

\footnotetext{
${ }^{2}$ The EPO directly records citations to other EPO patents. Goossen (2014) has built a crosswalk between EPO and USPTO citations that we use to build out the citations in our data set. That crosswalk does not include all of the information, such as the filing date, of USPTO material.
} 
Fleming \& Sorenson 2001). We model forward citation counts for patents that were granted. This is to maximize comparability with prior research, which has focused on the impact of granted patents.

Independent variable. To operationalize recombinant breadth, we calculate the breadth of each patent as per Gruber, Harhoff \& Hoisl (2013). A focal patent cites $J$ prior patents. Those references in turn cite work that is distributed across $K$ different technological domains (represented here by 4-digit IPC patent sub-classes). The share of domain $k \in K$ in $j \in J$ 's references is $s_{j_{k}}$. Let $S$ equal the total number of references to technological domains by all of the focal patent's $J$ citations. ${ }^{3}$ Summation is done recursively, first across patents within a technological domain and then across technological domains. Thus:

$$
B \equiv 1-\sum_{k=1}^{K}\left(\frac{\sum_{j=1}^{J} s_{j_{k}}}{S}\right)^{2}
$$

Intuitively, this measure tracks the focal patent's ties to prior bodies of knowledge; it increases when a patent references more bodies of work, and is down-weighted by how often those bodies of work reference one another. Breadth is bounded between zero and one. Figure 3 plots the kernel density of this measure. Many applications have zero breadth because they only include citations to a single technology domain. Replicating our analyses on the sub-sample of applications where breadth is greater than zero does not change our results.

Control variables. We include a canonical set of variables that prior work has found to be associated either with the granting of patents or with forward citation counts. We control for the number of backward citations, because there is a positive correlation between the amount of prior work patents cite and their own citation counts. We also control for the age of prior work, in order to control for how close a patent is to the current technological frontier; Nerkar (2003) also proposed that citing older patents represents a type of exploratory search that leads to better performance. Because work produced in teams has a greater impact (Wuchty, Jones \& Uzzi 2007), we control for the number of inventors on each patent application.

Finally, we control for the technological fertility of different patent classes. It is well known that the rate of change varies across technologies, and thus it is useful to control for the "expected"

\footnotetext{
${ }^{3}$ Unlike a traditional Herfindahl index, which counts unique references to each domain, the recombinant-breadth measure counts all references to each domain. See Gruber, Harhoff \& Hoisl (2013) for more details and comparison to related measures.
} 


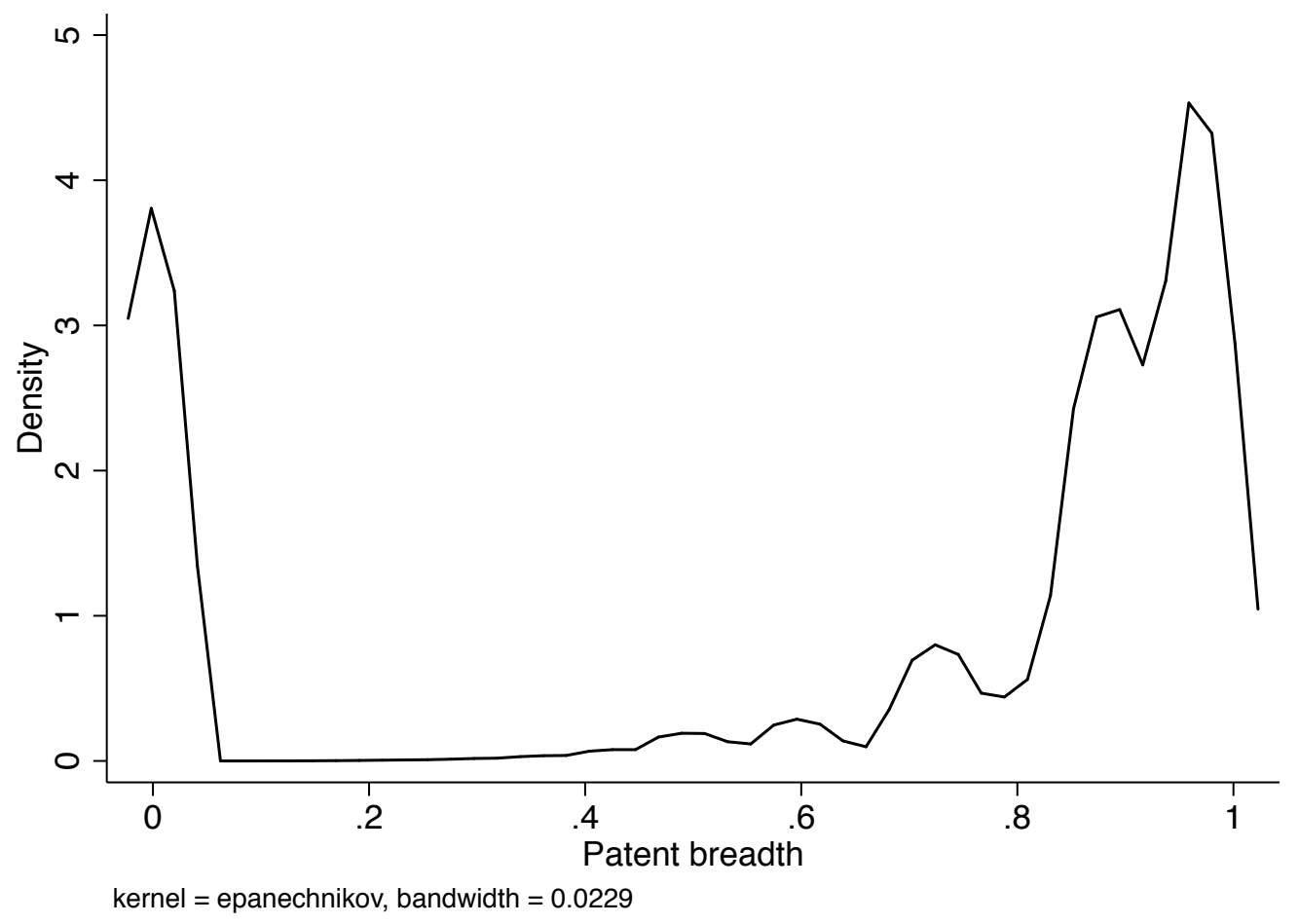

Figure 3: Kernel density of recombinant breadth

impact of patents in different technological classes (Fleming 2001). We operationalize technological fertility by averaging the citations a patent application's technological classes received in the previous five years, weighted by the number of sub-classes listed for each class.

Here we have described the predicted (mostly positive) coefficients for these control variables in terms of their effects on citation impact. We do not have off-the-shelf predictions for their effects on application approval, because prior work has not hypothesized about this stage. Table 1 lists summary statistics for each of these variables; table 2 presents bivariate correlations.

\section{Modeling strategy}

Our plan is to test for the effects of recombinant breadth on approval and impact, as well as on impact net of approval. Our main analyses therefore estimate patent granting and citation separately and then jointly. For approval, we estimate probit models of whether patents are granted. For impact, we estimate quasi-maximum-likelihood Poisson models (Wooldridge 1999) of five-year citation counts. To model the differential selection that approval induces on patent quality and thus on impact, we fit two-stage count models with selection. The latter involve estimating the 
Table 1: Summary statistics

\begin{tabular}{lccccc}
\hline \hline & Count & Mean & S.D. & Min & Max \\
\hline Patent-granting analysis & & & & & \\
Application granted & 844060 & 0.62 & 0.49 & 0 & 1 \\
Patent breadth & 844060 & 0.65 & 0.41 & 0 & 1 \\
$\ln$ (Backward citation count) & 844060 & 2.84 & 0.72 & 0 & 7.51 \\
$\ln$ (Inventor count) & 844060 & 0.70 & 0.62 & 0 & 3.89 \\
$\ln$ (Tech. fertility) & 844060 & 26.10 & 1.26 & 18.23 & 29.82 \\
Art-unit workload & 844060 & 0.02 & 0.19 & -2.37 & 1.64 \\
\hline Patent-citation analysis Forward citation count & 519476 & 18.10 & 37.56 & 1 & 3690 \\
Patent breadth & 519476 & 0.64 & 0.41 & 0 & 1 \\
$\ln$ (Backward citation count) & 519476 & 2.85 & 0.72 & 0 & 7.22 \\
$\ln$ (Avg. citation age) & 519476 & 9.43 & 0.20 & 8.84 & 9.84 \\
$\ln$ (Inventor count) & 519476 & 0.72 & 0.62 & 0 & 3.64 \\
$\ln$ (Tech. fertility) & 519476 & 25.96 & 1.22 & 19.14 & 29.82 \\
Inverse Mills ratio & 519476 & 2.05 & 0.34 & 1.27 & 3.00 \\
\hline \hline
\end{tabular}

Table 2: Bivariate correlations

\begin{tabular}{lcccccccc}
\hline \hline & $(1)$ & $(2)$ & $(3)$ & $(4)$ & $(5)$ & $(6)$ & $(7)$ & $(8)$ \\
\hline (1) Patent granted & 1.00 & & & & & & & \\
(2) Number forward cites & 0.14 & 1.00 & & & & & & \\
(3) Patent breadth & -0.06 & 0.04 & 1.00 & & & & & \\
(4) $\ln$ (Backward citation count) & -0.06 & 0.06 & 0.25 & 1.00 & & & & \\
(5) $\ln$ (Avg. citation age) & -0.32 & -0.12 & 0.08 & 0.13 & 1.00 & & & \\
(6) $\ln$ (Inventor count) & -0.04 & 0.06 & 0.11 & 0.12 & 0.10 & 1.00 & & \\
(7) $\ln$ (Tech. fertility) & -0.33 & -0.11 & 0.10 & 0.10 & 0.60 & 0.19 & 1.00 & \\
(8) Art-unit workload & -0.04 & -0.00 & -0.01 & 0.00 & 0.00 & 0.01 & 0.01 & 1.00 \\
\hline \hline
\end{tabular}


full approval model, then calculating an inverse Mills ratio for each patent application showing its predicted probability of being granted, and including this ratio in subsequent count models of impact. Greene (1994) has shown that such a procedure yields unbiased and efficient estimates of coefficients in the second stage (see Wang \& Soule (2012) for a recent application), and other innovation research has used the same procedure to model other kinds of selection bias (Fleming, Mingo \& Chen 2007). Additionally, using the inverse Mills ratio within a second-stage model allows us to treat the models controlling and not controlling for sample selection as nested, which makes their coefficients directly comparable.

To satisfy the exclusion restriction in the approval stage, we require a variable that is correlated with approval but uncorrelated with citation impact conditional on approval. We measure variation in workloads that patent examiners face when a given application is filed. Previous work on researchgrant proposals (Criscuolo, Dahlander, Grohsjean \& Salter 2016) and patents (Chaffin, Heidl, Chari \& Calantone 2013) has shown a negative relationship between the workload that reviewers face and their approval rates. Within an art unit at the patent office, the workload in any given period is determined by the decisions of many other inventors to file applications, and thus can be treated as quasi-exogenous to the focal applicant's decision to file. Variations in an art unit's workload should affect an application's chances of being granted, but not the subsequent citations it receives. We focus on idiosyncratic variations in art-unit workload, above and beyond those predicted by any secular trends or differences between the art units. For details of how we construct and validate an instrument using art-unit workload, see appendix B. Summary statistics and correlations for this variable are presented in tables 1 and 2 .

\section{Results}

As an initial cut through the data, table 3 presents approval rates and citation counts for inventions in different swathes of the breadth distribution. We present average citation counts for successful and failed applications. (For details on how failed applications receive citations in the EPO system, see appendix C.) The first two rows show that applications with above-median breadth are about 6 percent less likely to be approved than those below the median. A comparison of citation counts suggests that this is not because broader inventions have lower quality. Successful broad applications 
receive more citations than successful narrow applications (20.51 versus $16.45, p<.01)$. More importantly, broad inventions whose applications fail also receive more citations than similarly failed narrow inventions $(10.42$ v. 8.36, $p<.01)$. This inverse relationship between approval and citation rates is even more striking if we compare the top and bottom quartiles of the breadth distribution, as in the bottom two rows. Applications in the top quartile of breadth are nearly 10 percent less likely to be granted than applications in the bottom quartile. Yet failed applications with high breadth are as likely to be cited as successful applications with low breadth (11.61 v. 11.39, $p<.28)$. Across all conditions, broader inventions draw more citations, which jibes with innovation research on knowledge recombination. Yet in each condition, broader applications seem less likely to be approved. We further explore this relationship in a multivariate framework below.

Table 3: Approval rates for high- and low-breadth patent applications, and citation counts conditional on approval

\begin{tabular}{|c|c|c|}
\hline & $\begin{array}{l}\text { Approval } \\
\text { rate }\end{array}$ & $\begin{array}{l}\text { Citation } \\
\text { count }\end{array}$ \\
\hline Breadth $>p(50)$ & .592 & $\begin{array}{r}\text { Not approved:10.42 } \\
\text { Approved:20.51 }\end{array}$ \\
\hline Breadth $<p(50)$ & $\begin{array}{c}------ \\
.630\end{array}$ & $\begin{array}{l}\text { Not approved:8.36 } \\
\text { Approved: } 16.45\end{array}$ \\
\hline $\begin{array}{c}\text { Breadth }>p(75) \\
\text { Breadth }<p(25)\end{array}$ & $\begin{array}{c}.577 \\
------ \\
.638\end{array}$ & $\begin{array}{c}\text { Not approved:11.61 } \\
\text { Approved:21.99 } \\
\text { Not approved:7.89 } \\
\text { Approved:11.39 }\end{array}$ \\
\hline
\end{tabular}

Calculated on all patent applications filed at the EPO between 1983 and 2007, and patents granted by the EPO between 1984 and 2008. See appendix $\mathrm{C}$ for details on how citations are made to failed patent applications.

In table 4 we present probit-model results for whether broad knowledge recombinations hurt approval. The coefficient on recombinant breadth in these models can be interpreted as an estimate of the size of parameter $A$, approval hurdles that produce differential selection, from figure 1. In addition to the listed covariates, each of these models includes fixed effects for the year the application was filed. Standard errors are clustered by the art units of the application, because the art-unit workload instrument is calculated at this level.

Model 1 shows that the relationship between breadth and the likelihood of patent being granted to an application is negative and significant. Given the large sample size, statistical significance is almost guaranteed in such models; therefore it is worth noting that the magnitude of the coefficient 
is also substantial. Increasing recombinant breadth from zero to one reduces the probability of an application's being granted patent by about 6 percent. This coefficient size remains basically unchanged across the models. This supports hypothesis 1 .

Table 4: Probit models predicting granting of patent application

\begin{tabular}{lccc}
\hline \hline & $(1)$ & $(2)$ & $(3)$ \\
\hline Patent breadth & $-0.091^{* * *}$ & $-0.101^{* * *}$ & $-0.101^{* * *}$ \\
& $(0.020)$ & $(0.019)$ & $(0.019)$ \\
$\ln$ (Backward citation count) & & $0.029^{* * *}$ & $0.029^{* * *}$ \\
& & $(0.008)$ & $(0.008)$ \\
$\ln$ (Inventor count) & $0.104^{* * *}$ & $0.104^{* * *}$ \\
& & $(0.006)$ & $(0.006)$ \\
$\ln$ (Tech. fertility) & & $-0.072^{* * *}$ & $-0.072^{* * *}$ \\
& & $(0.011)$ & $(0.011)$ \\
Art-unit workload & & $-0.028^{* * *}$ \\
& & & $(0.008)$ \\
Filing-year F.E.s & $\mathrm{Y}$ & $\mathrm{Y}$ \\
Constant & $0.763^{* * *}$ & $2.270^{* * *}$ & $2.853^{* * *}$ \\
& $(0.067)$ & $(0.257)$ & $(0.271)$ \\
\hline Observations & 844060 & 844060 & 844060 \\
Log-likelihood & -550594 & -548496 & -548485 \\
\hline \hline Models are estimated on all patent applications with non-missing data filed \\
at the EPO between 1983 and 2007. & & \\
Standard errors, clustered by patent art units defined at the four-digit IPC \\
level, are in parentheses. \\
${ }^{*} p<0.05,{ }^{* *} p<0.01,{ }^{* * *} p<0.001$
\end{tabular}

Model 2 introduces controls for the count of backward citations, inventors, and technological fertility. Inventor counts and technological fertility have negative associations with approval. We do not have a strong interpretation of this result. Domains with more citation activity may also be more competitive; that crowding effect may predominate in approval. Model 3 controls for the effect of the relevant art units' workloads at time of application, per our exclusion restriction. Increased workloads in the art units are associated with lower approval rates. The coefficient on recombinant breadth remains unchanged between models 2 and 3. All of these models show that more recombination, operationalized as greater breadth, is associated with lower rates of approval.

We saw in table 3 that the impact of breadth on approval was larger at more extreme comparisons of breadth values. This raises the question whether the impact of breadth is itself linear across the range of support of the data. It may be for example that the organizational difficulties of examining applications scale not in the number of classes spanned but in the number of possible 


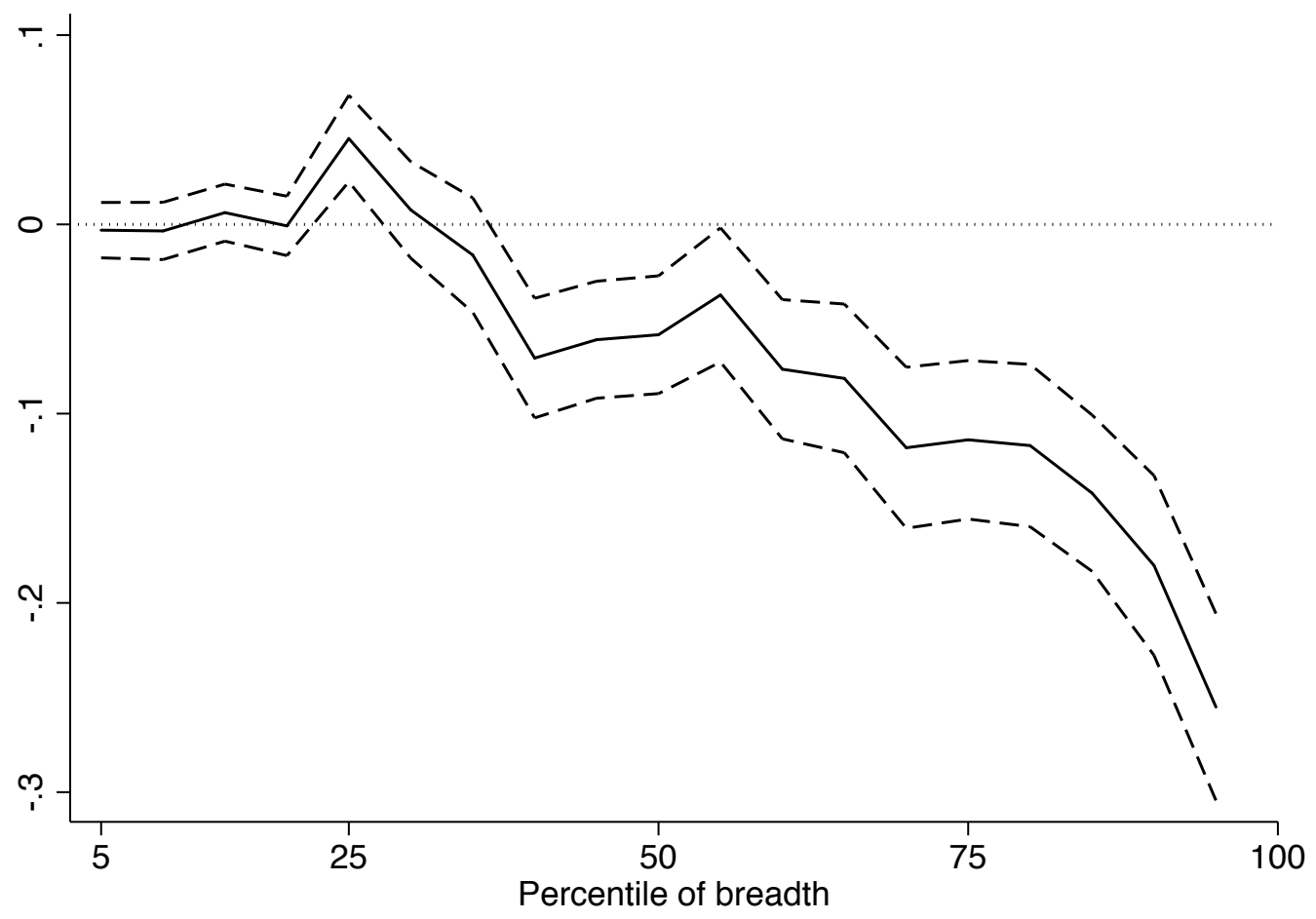

Figure 4: Impact of patent-application breadth on approval rates, estimated at different points in the breadth distribution.

combinations, which grows more quickly. And given the distribution of our breadth variable, it is useful to know where its effects are largest relative to the mass of the data. To explore this, we divided our data into 20 groups representing 5-percentage-point buckets of the breadth distribution. We then re-fit model 3 on each of these groups. Figure 4 shows the estimated coefficients. ${ }^{4}$ Through the first quartile of the distribution, breadth is not associated with any significant impact on application approval rates. In the fourth quartile, meanwhile, the negative association is considerably stronger than in the middle half of the distribution. Since the patent-breadth variable is bimodal, the coefficients represented in figure 4 imply that many patents face even larger penalties for spanning multiple classes than the pooled coefficient in model 3 would suggest.

Next we examine how recombinant patents perform once they have been granted. In table 5 we present QML Poisson models estimating the impact of granted patents. Here the coefficient on recombinant breadth can be interpreted as an estimate of parameter $M *$, impact benefits conflated with differential selection, in figure 1. These models include fixed effects for the year the application

\footnotetext{
${ }^{4}$ We thank an anonymous reviewer for this idea.
} 
was filed as well as for the year it was granted, and the standard errors are clustered as in table 4. Model 4 shows that, as previous studies have found, greater breadth in granted patents is associated with higher forward citation counts and thus greater impact. This supports hypothesis 2. Model 5 introduces controls for the backward citation count, the age of backward citations (Nerkar 2003), and the count of the patent's inventors, and technological fertility; all move in the expected directions. Taken together, the controls introduced in models 5 reduce the estimated effect size of recombinant breadth by about half.

Table 5: QML Poisson models predicting forward-citation impact of granted patents

\begin{tabular}{lccc}
\hline \hline & $(4)$ & $(5)$ & $(6)$ \\
\hline Patent breadth & $0.211^{* * *}$ & $0.090^{* * *}$ & $0.056^{* * *}$ \\
& $(0.006)$ & $(0.006)$ & $(0.014)$ \\
$\ln$ (Backward citation count) & & $0.145^{* * *}$ & $0.135^{* * *}$ \\
& & $(0.005)$ & $(0.006)$ \\
$\ln$ (Avg. citation age) & & $1.120^{* * *}$ & $1.121^{* * *}$ \\
& & $(0.025)$ & $(0.025)$ \\
$\ln$ (Inventor count) & & $0.158^{* * *}$ & $0.160^{* * *}$ \\
& & $(0.005)$ & $(0.005)$ \\
$\ln$ (Tech. fertility) & & $0.142^{* * *}$ & $0.119^{* * *}$ \\
& & $(0.003)$ & $(0.009)$ \\
Inverse Mills ratio & & & $-0.317^{*}$ \\
& $\mathrm{Y}$ & $\mathrm{Y}$ & $(0.130)$ \\
Filing-year F.E.s & $\mathrm{Y}$ & $\mathrm{Y}$ & $\mathrm{Y}$ \\
Granting-year F.E.s & $2.524^{* * *}$ & $-10.778^{* * *}$ & $-9.385^{* * *}$ \\
Constant & $(0.005)$ & $(0.222)$ & $(0.602)$ \\
\hline Observations & 519475 & 519475 & 519475 \\
Log-likelihood & -6877487 & -6585040 & -6584911 \\
\hline \hline
\end{tabular}

Models are estimated on all patents with non-missing data filed with the EPO between 1983 and 2007 and granted by the EPO between 1984 and 2008 .

Standard errors, clustered by patent art units defined at the four-digit IPC level, are in parentheses.

${ }^{*} p<0.05,{ }^{* *} p<0.01,{ }^{* * *} p<0.001$

Models 4 and 5 essentially reproduce findings from previous studies. These models are estimated on granted patents, without taking sample selection into account. In model 6, we present a QML Poisson model with selection by including the inverse Mills ratio estimated for each patent based on the results from model 3. Accounting for selection reduces the estimated performance benefit of boundary spanning by about a third. A Wald test of equality of the coefficients on breadth in models 5 and 6 rejects the null hypothesis $\left(\chi^{2}=5.97, p<0.015\right)$. We interpret this coefficient as 


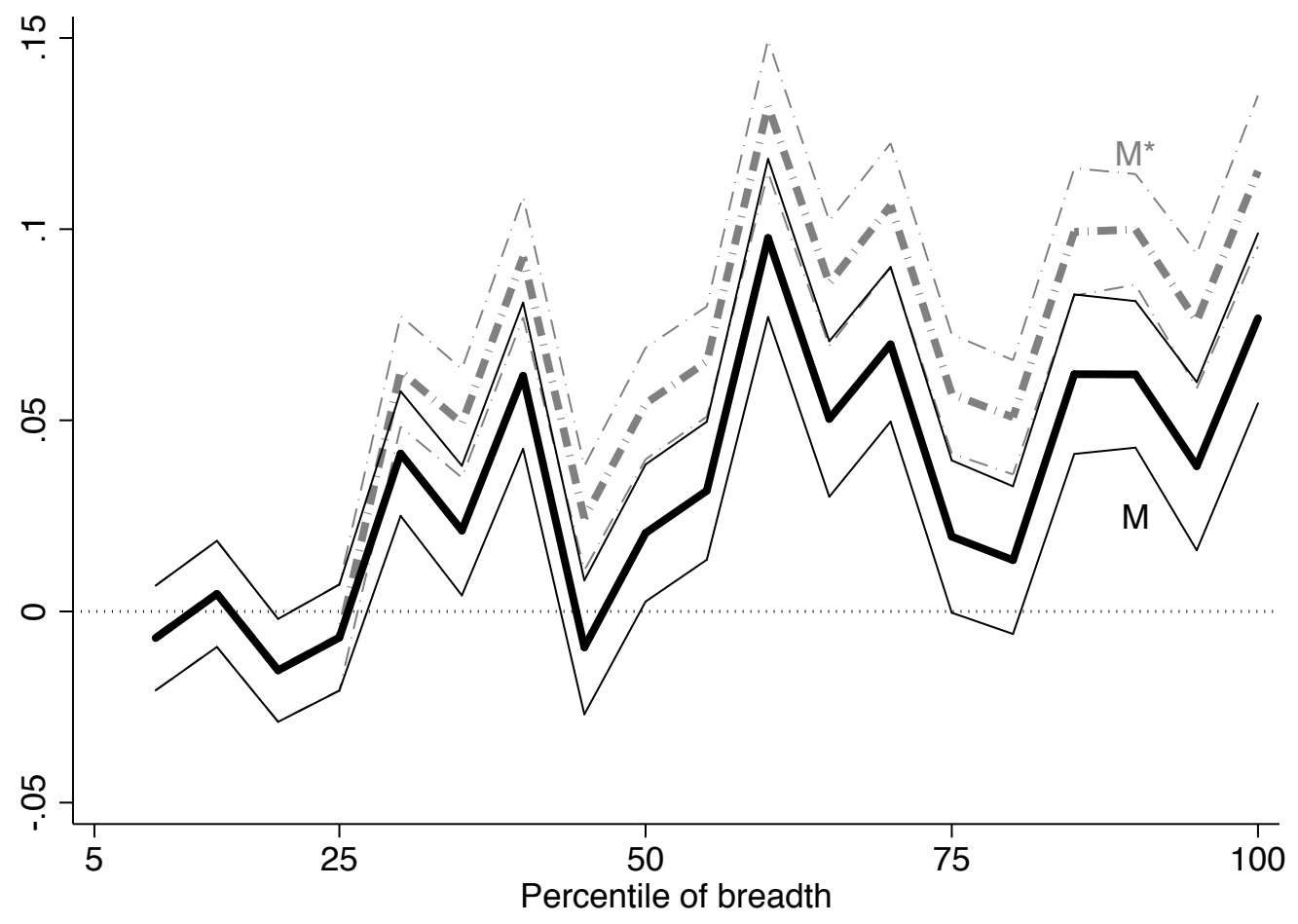

Figure 5: Impact of patent-application breadth on citation impact, estimated at different points in the breadth distribution. $M *$ shows impact without correcting for sample selection. $M$ shows corrected predictions.

an estimate of parameter $M$, the effect on impact once the overstatement caused by the approval process is accounted for. This reduction in size from $M *$ to $M$ supports hypothesis 3 .

As with approval, we estimated the impact of breadth on citations at different points in the distribution. Figure 5 shows coefficients for breadth on impact with $(M)$ and without $(M *)$ correcting for sample selection. As one might predict from previous work, the patents with the broadest knowledge recombination have the greatest citation impact. Yet since these patents are from the portion of the application pool with the strongest sample selection, correcting for selection reduces the estimate of impact considerably. Patents at the 90th percentile of breadth have citation impacts comparable to those predicted for patents at the median breadth in the uncorrected models.

Taken together, these results suggest that the role that recombinant breadth plays in the approval and impact of patents resembles panel IV in figure 2. That is to say, we find strong evidence, consistent with prior studies, that broader patents do have a higher mean impact than narrower ones. At the same time, we find strong evidence that broader patent applications are less likely be granted. This differential selection reflects institutional gatekeeping: among broader applications, 
examiners only approve the higher-quality ones, and thus the impact of lower-quality, broad applications is not observed. This overstates the observed relationship between knowledge recombination and innovation impact.

\section{Does the typicality of the combination matter?}

As we discussed at the start, we have focused on the effect of recombinant breadth, not on the effect of typicality or familiarity, on patent approval and citation rates. We chose this focus because we have emphasized the organizational problems that we think broad applications pose for examiners (see appendix A), and we think that recombinant breadth poses the main problem. Because the examiner's remit is to demarcate an invention's novel and inventive contribution relative to what has come before, the challenge of commensurating different bodies of technical knowledge should be central. Yet there are two reasons to consider how atypical technological combination is, alongside how broad it is. First, research has found that it is not just the breadth of a technological combination that influences a patent's impact, but also its typicality. Second, especially because some studies of boundary spanning in other gatekeeping settings have considered breadth and typicality together (e.g., (Kovacs \& Hannan 2011)), it seems important to check whether the effects we have hypothesized for breadth hold when controlling for typicality.

A combination's typicality measures the extent to which that combination has been used in the past by the broader technological community. Combination typicality has a complex, non-linear effect on patent citations. Fleming (2001) shows that combination typicality increases the mean impact of a patent but reduces its variance. He also shows that mean citation impact declines at increasing levels of typicality, because familiarity with a combination reduces its novelty. In a study of scientific publications, Uzzi et al. (2013) show that citation rates are maximized when publications build on a large body of conventional knowledge combinations enriched by a small share of highly atypical ones: "[T]he highest-impact science is primarily grounded in exceptionally conventional combinations of prior work yet simultaneously features an intrusion of unusual combinations" (p. 468).

With regard to the institutional-gatekeeping stage, the extant literature offers no direct empirical evidence or clear theoretical expectation for the impact of typicality on patent approval. On the one hand, because Fleming (2001) and Uzzi et al. (2013) demonstrate that the presence of atypical 
combinations is characteristic of extraordinary innovations, patent examiners might be more likely to recognize novelty and inventiveness - hence patentability - in applications containing atypical combinations. On the other hand, categorization research has argued that atypical combinations are harder to understand (Kovacs \& Hannan 2011), which could lower the likelihood of approval for inventions with atypical combinations. Although our model is agnostic about the effect of combination typicality on approval and impact, both represent interesting empirical questions that can add context to our main results.

One way to measure the typicality of combinations in a patent application is with the Jaccard index, which is widely employed to compare the similarity of different sets. Formally, the Jaccard of sets $A$ and $B$ is defined as the intersection of the sets divided by their union: $J(A, B)=\frac{A \cap B}{A \cup B}$. Intuitively, the Jaccard quantifies how likely the members of two sets are to be observed together, relative to their being observed separately. Higher values of the index imply that combinations of $A$ and $B$ are more typical.

For each patent application, we calculated the Jaccard index for each of its combinations of fourdigit IPC classes. We then calculated the minimum Jaccard for each application. Lower minimum Jaccards reflect more atypical technological recombinations within an application. The Jaccard is not defined for single-class patent applications, so results using this measure are estimated on the sub-sample of applications with citations to more than one technology class. The Jaccard has a low correlation $(\rho=.068)$ with our measure of breadth, so we can examine models that include both variables.

Table 6 reproduces our models of patent approval using the minimum Jaccard rather than recombinant breadth. Higher values for the Jaccard are associated with lower levels of patent approval. The interpretation of the coefficients in table 6 is worth spelling out. More typical combinations, on average, are associated with lower rates of application approval. Figure 6 plots this effect for different levels of the Jaccard; it makes clear that these approval penalties are associated with particularly high levels of typicality among combinations. Model 10 shows that the effects we find for recombinant breadth are unaffected when separately controlling for typicality.

These typicality results tell us something important about institutional gatekeeping in the patenting process. They say that an application with a particularly low minimum Jaccard-one that combines knowledge that has rarely been combined before-may be difficult as an invention 
Table 6: Probit models predicting granting of patent application, using minimum Jaccard

\begin{tabular}{lcccc}
\hline \hline & $(7)$ & $(8)$ & $(9)$ & $(10)$ \\
\hline Minimum Jaccard & $-1.004^{* * *}$ & $-0.926^{* * *}$ & $-0.918^{* * *}$ & $-0.907^{* * *}$ \\
& $(0.149)$ & $(0.128)$ & $(0.127)$ & $(0.124)$ \\
Patent breadth & & & & $-0.112^{* * *}$ \\
& & & & $(0.009)$ \\
$\ln$ (Backward citation count) & & $-0.067^{* * *}$ & $-0.067^{* * *}$ & $-0.056^{* * *}$ \\
& & $(0.006)$ & $(0.006)$ & $(0.006)$ \\
$\ln$ (Inventor count) & & $-0.027^{* * *}$ & $-0.026^{* * *}$ & $-0.023^{* *}$ \\
& & $(0.007)$ & $(0.007)$ & $(0.007)$ \\
Art-unit workload & & & $-0.087^{* * *}$ & $-0.086^{* * *}$ \\
& & & $(0.013)$ & $(0.013)$ \\
Filing-year F.E.s & $\mathrm{Y}$ & $\mathrm{Y}$ & $\mathrm{Y}$ & $\mathrm{Y}$ \\
Constant & $0.801^{* * *}$ & $1.014^{* * *}$ & $1.013^{* * *}$ & $1.062^{* * *}$ \\
& $(0.025)$ & $(0.038)$ & $(0.038)$ & $(0.040)$ \\
\hline Observations & 638889 & 638889 & 638889 & 638889 \\
Log-likelihood & -371973 & -371422 & -371326 & -371124 \\
\hline \hline
\end{tabular}

See table 4 for details on the main sample. Models here are estimated on patent applications where the application lists two or more IPC classes. The Jaccard is not defined for single-class cases - hence the smaller number of observations compard to table 4 .

Standard errors, clustered by patent art units defined at the four-digit IPC level, are in parentheses.

${ }^{*} p<0.05,{ }^{* *} p<0.01,{ }^{* * *} p<0.001$

for the examiner to make sense of, but it more clearly represents something new in the world. And indeed we find that low typicality does not have approval hurdles associated with it. This finding is consistent with research that emphasizes how atypical combinations are marks of novelty and inventiveness (Uzzi et al. 2013, Mukherjee, Uzzi, Jones \& Stringer 2016, Wuchty, Jones \& Uzzi 2007). But it differs from categorization research on the benefits of typicality. That research posits that atypical combinations are harder to understand. Our finding does not contradict this idea. In our setting, though, such cognitive difficulties appear to be offset by how extreme atypicality can also signal novelty and inventiveness, which are key value criteria for patent examiners. In contexts where institutional gatekeepers care less about novelty or inventiveness, the cognitive difficulties associated with atypicality may well dominate.

We next analyze typicality's impact on citations. As noted, Uzzi et al. (2013) and Mukherjee et al. (2016) have discussed how impactful innovations are based neither on entirely atypical nor on completely conventional combinations. In table 7 we present citation-impact results using the minimum-Jaccard measure. The coefficient on the Jaccard in these models is negative; more typical 


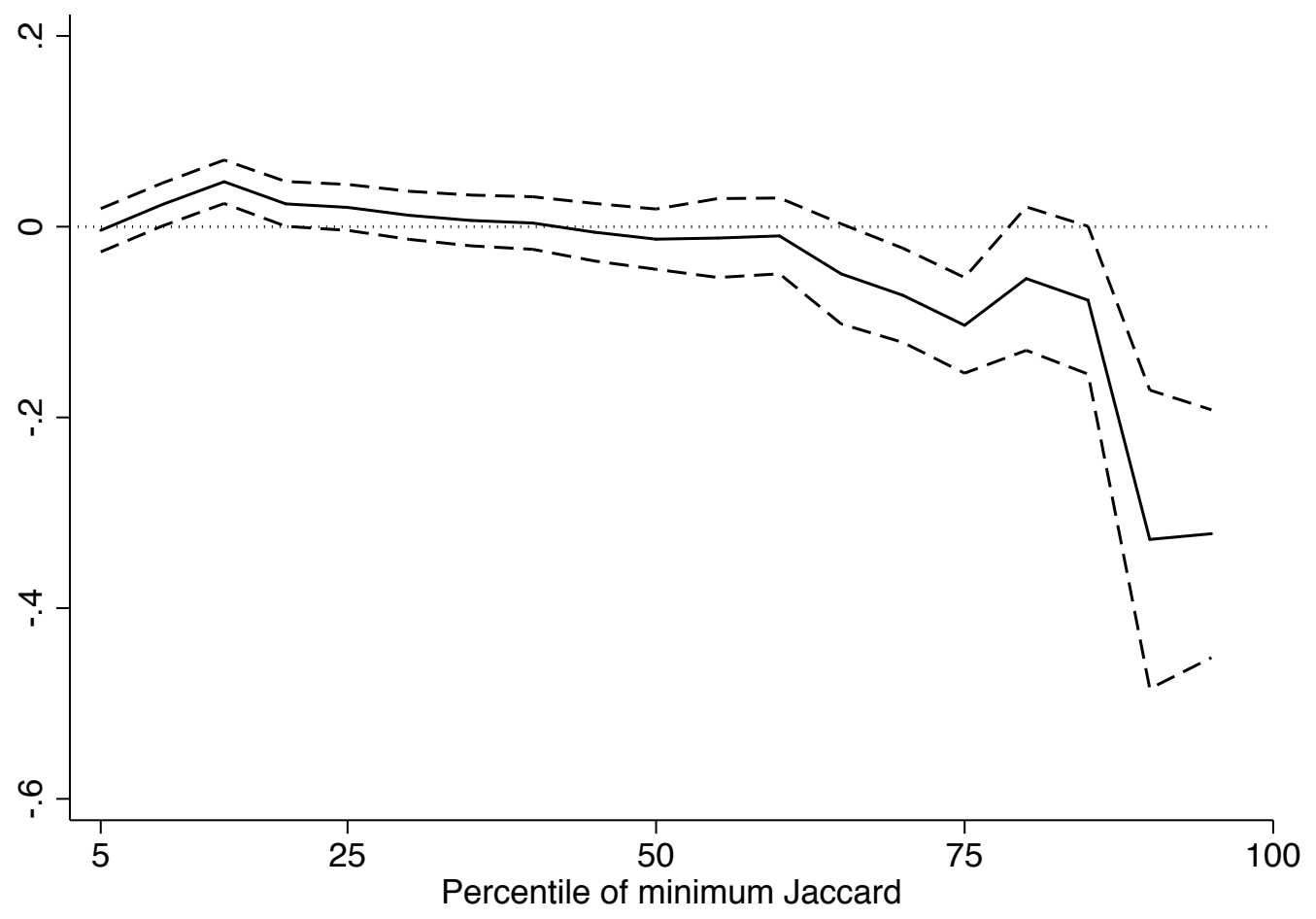

Figure 6: Impact of minimum patent-application Jaccard on approval rates, estimated at different points in the Jaccard distribution.

patents amass fewer citations over time. There is little evidence when comparing the coefficients in models 12 and 13 that accounting for selection mediates the citation impact of typicality the way it does for breadth. This is even clearer in figure 7, which plots citation impact across the minimumJaccard distribution, paralleling figure 5. Since applications with high and low breadth can be found at most points on the typicality spectrum (per the low correlation of the variables), ignoring selection does not bias our interpretations of the effect of typicality on impact. Some mediation of the Jaccard appears in models 14 and 15, where we simultaneously control for recombinant breadth, but our main finding is still supported. Even when controlling for typicality, we find substantively similar effects of recombinant breadth on citation impact, and substantively similar mediation when controlling for selection.

\section{Additional analyses and robustness checks}

We have based our measure of recombinant breadth on that developed by Gruber, Harhoff \& Hoisl (2013). That study compares its robustness favorably to other, similar measures of recombinant 
Table 7: QML Poisson models predicting forward-citation impact of granted patents, using minimum Jaccard

\begin{tabular}{lccccc}
\hline \hline & $(11)$ & $(12)$ & $(13)$ & $(14)$ & $(15)$ \\
\hline Minimum Jaccard & $-0.784^{* * *}$ & $-1.078^{* * *}$ & $-1.114^{* * *}$ & $-1.081^{* * *}$ & $-0.566^{* * *}$ \\
& $(0.040)$ & $(0.042)$ & $(0.085)$ & $(0.043)$ & $(0.133)$ \\
Patent breadth & & & & $0.103^{* *}$ & $0.034^{* * *}$ \\
& & & & $(0.020)$ & $(0.011)$ \\
$\ln$ (Backward citation count) & & $0.153^{* * *}$ & $0.150^{* * *}$ & $0.150^{* * *}$ & $0.183^{* * *}$ \\
& & $(0.006)$ & $(0.008)$ & $(0.007)$ & $(0.010)$ \\
$\ln$ (Avg. citation age) & & $1.225^{* * *}$ & $1.224^{* * *}$ & $1.221^{* * *}$ & $1.221^{* * *}$ \\
& & $(0.036)$ & $(0.036)$ & $(0.036)$ & $(0.036)$ \\
$\ln$ (Inventor count) & & $0.158^{* * *}$ & $0.157^{* * *}$ & $0.157^{* * *}$ & $0.171^{* * *}$ \\
& & $(0.007)$ & $(0.007)$ & $(0.007)$ & $(0.008)$ \\
Inverse Mills ratio & & & -0.048 & & $0.717^{* * *}$ \\
& & & $(0.095)$ & & $(0.175)$ \\
Constant & $1.651^{* * *}$ & $-9.965^{* * *}$ & $-9.822^{* * *}$ & $-9.951^{* * *}$ & $-12.036^{* * *}$ \\
& $(0.240)$ & $(0.389)$ & $(0.479)$ & $(0.389)$ & $(0.637)$ \\
\hline Observations & 266175 & 266175 & 266175 & 266175 & 266175 \\
Log-likelihood & -4088206 & -3953089 & -3953081 & -3952795 & -3952306 \\
\hline \hline
\end{tabular}

See table 5 for details on the main sample. Models here are estimated on all patents with two or more IPC classes. The Jaccard is not defined for single-class cases-hence the smaller number of observations compared to table 5.

Standard errors, clustered by patent art units defined at the four-digit IPC level, are in parentheses.

${ }^{*} p<0.05,{ }^{* *} p<0.01,{ }^{* * *} p<0.001$ 


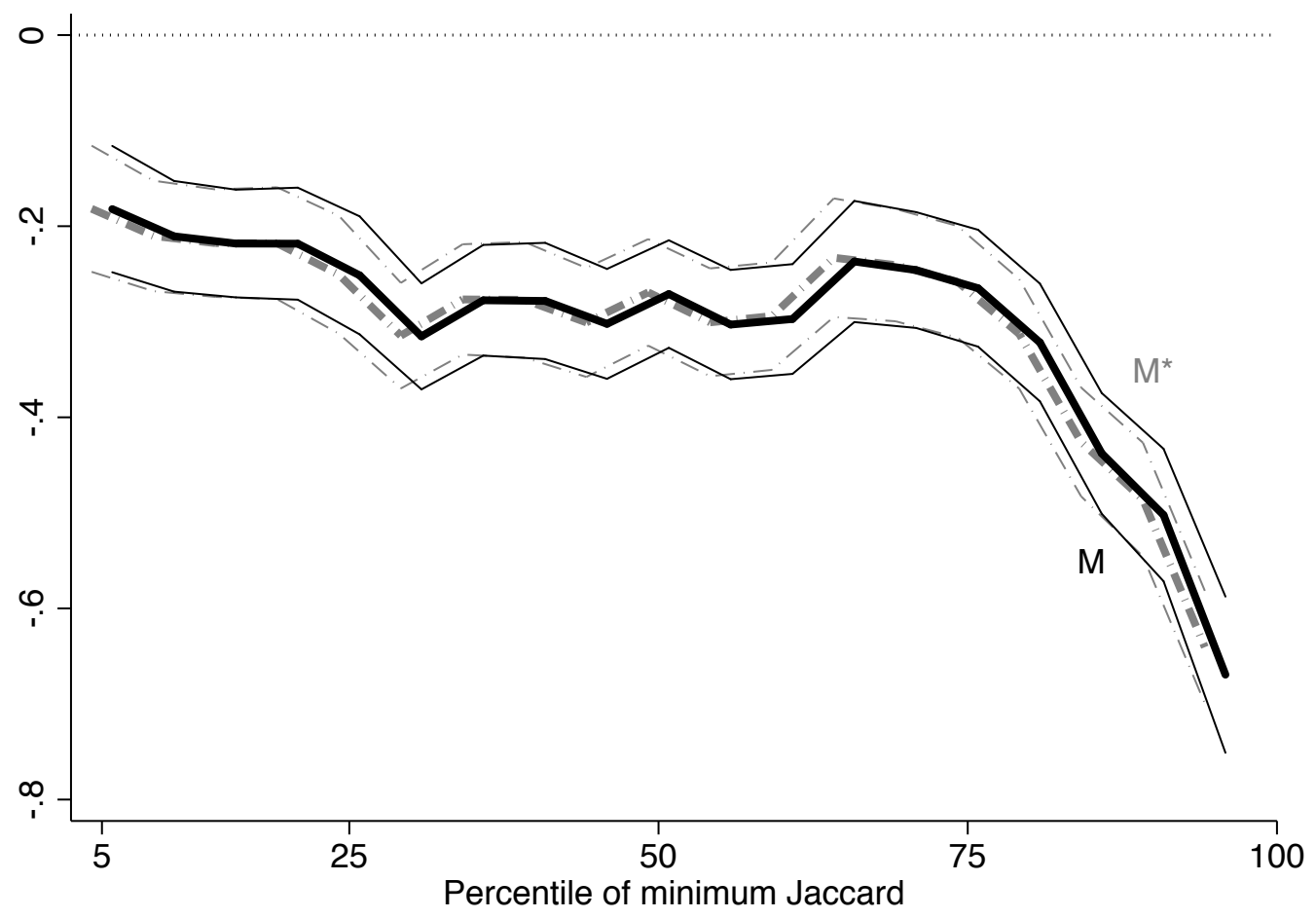

Figure 7: Impact of minimum patent-application Jaccard on citation impact, estimated at different points in the Jaccard distribution. $M *$ shows impact without correcting for sample selection. $M$ shows corrected predictions.

breadth that have been proposed and used in innovation research (cf. Lerner (1994) and Leahey (2006)). All such measures are highly correlated with one another, and indeed with a Herfindahl index of the focal patent's prior art's citations. We show in appendix D that using another of these related measures does not substantively change our results.

We also wanted to ensure that our results were not dependent on our treatment of "pending" applications. In discussing how institutional gatekeeping by patent examiners can influence the innovation process, we have emphasized how recombinant breadth affects the likelihood that an application is granted. Because they compare applications that were granted to those that were rejected or withdrawn, our probit models ignore the large number of patent applications that are pending at any given time. This could bias our results. We explore this question in greater detail in appendix E. While we find that broader patent applications do spend longer in review, accounting for this does not substantively alter our results.

Whereas Fleming (2001) explores the effects of combination typicality using a continuous measure, Uzzi et al. (2013) posit that what really matters is whether a combination is radically new. 
The results for both recombinant breadth and for the minimum Jaccard suggest that the greatest approval penalties apply to inventions that span many domains of knowledge that have been spanned many times before. To give full credit to the idea of radical innovation, we also created a dummy variable, radical novelty, which flags applications that have citations to technology classes that have never been combined in any previous patent applications. This type of novelty is extremely rare; brand-new combinations appear in only 0.24 percent of our observations. We augmented our main analysis with this novelty variable and found that radical novelty is associated with both higher approval rates and more citations. Yet there is no significant interaction between breadth and novelty in such models (full results available on request). We also examined radical novelty's effects on review time; see appendix E.

Finally, we fit several other models to investigate the relationship between breadth and typicality. We fit our main models on the subset of observations where breadth is greater than zero, which parallels the subset on which the Jaccard is defined; and we also fit models using the mean rather than the minimum Jaccard. Full results are in appendix F.

\section{Discussion and conclusion}

In this paper, we advance theory on the benefits of knowledge recombination by putting forth a more institutionally informed model, one that accounts for the role of the patent office during the innovation process. We argue that it is useful to think of patent examiners in light of research on institutional gatekeeping, and to study how gatekeeping might influence the population of granted patents. Specifically, the impact of lower-quality broad recombinations is not observed, and so estimates of the relationship between recombinant breadth and innovation impact that do not account for differential selection are upwardly biased. We show this pattern of results in data on patent applications and citations from the European Patent Office.

Innovation researchers have repeatedly used patent data to explore benefits that result from seeking out and combining diverse knowledge (Fleming 2001, Rosenkopf \& Nerkar 2001, Nerkar 2003, Fleming, Mingo \& Chen 2007, Carnabuci \& Bruggeman 2009). Patent data are among our best empirical sources for information about innovation. They provide large-scale, fine-grained detail on the spread of knowledge and the ties between ideas. The results we present here do not 
overturn our basic understanding of the benefits of recombinant breadth for innovation. They do suggest though that building a more detailed institutional model of the innovation process can qualify or modify important theoretical relationships that have only been tested on outcome data. Particularly when the effect of interest could affect whether an application is granted patent, our collective understanding would be improved by taking institutional gatekeeping into account.

The question remains, why might examiners apply different thresholds to more recombinant patent applications in the first place? We argue (see appendix A) that the division of labor within the patent office, combined with the difficulties of discerning the contributions of a boundaryspanning invention to multiple, specialized technology domains, means that patent applications with broader knowledge recombination are less likely to be approved than more narrowly focused ones of equal quality. We offer some indirect evidence (see appendix E) that the examiners do find it more difficult to suss out the contributions of broader applications, by showing that said applications spend longer under review. But more work on the decision-making routines of examiners is clearly needed.

We have focused on the mean effects of recombinant breadth in this paper, but our results also have implications for the mean effects of typicality. Studies of patent typicality often collapse breadth and familiarity into single measures (Kovacs \& Hannan 2011). Because we think that there are conceptually distinct issues pertaining to selection on these dimensions, we think that it is theoretically and empirically useful to separate out their effects in innovation research. For example, it is worth noting why controlling for selection does not change the estimated effect of typicality on citations, while it does change that of breadth. Figure 6 shows that approval hurdles are highest at very high levels of typicality. Yet figure 7 shows that high typicality is not associated with particularly high levels of citation. Thus the fact that examiners devalue high-typicality applications contributes little selection bias, because inventors seem to devalue them as well. This is quite different from the results in figures 4 and 5, which show that examiners' devaluation of broader applications bites in the part of the population that future inventors seem to value. On this dimension, because the decision-making process of the two actors differs, differential selection results. This points toward a strategy for future research exploring institutional gatekeeping: specify the decision-making criteria of the different stages and focus on those places where the criteria differ. 
Our results also speak to the effects of knowledge recombination on the variance of citation impact found in prior studies. Innovation research has tended to assume that, because the (observable) citation distribution of recombinant patents is more heavily skewed than the citation distribution of non-recombinant patents, then the (unobservable) quality distribution of recombinant inventions must also be more heavily skewed than the quality distribution of non-recombinant inventions. That heavier skew, in turn, is theorized to account for the greater variance in citation impact for recombinant patents. Our results do not contradict this assumption. Our model though — which assumes patent examiners applying different thresholds, as well as different shapes in the quality distributions - offers an alternative prediction about the variance in citations to recombinant patents. If the population of granted recombinant patents is more truncated then the population of granted non-recombinant patents, then the variance of citations to recombinant patents will appear smaller. We have shown that ignoring selection may overstate the mean effect of knowledge recombination on innovation impact. It may also understate the variance effect of knowledge recombination. This is a promising question to address in future research.

While our focus is on the patent office, our approach could be extended to other gatekeeping institutions. Recent scholarship has noted that gatekeeping institutions are ubiquitous in knowledgebased societies (Coffee Jr 2006) and that they subtly but deeply shape a variety of important phenomena, such as the diffusion of news among the public (Andrews \& Caren 2010), the adoption of responsible corporate practices (Slager, Gond \& Moon 2012), and the choice of medical technologies within hospitals (McNeil \& Minihan 1977). While the multitude of gatekeeping institutions regulating contemporary markets can hardly be subsumed within a single organizational form, the principal function of most of them is to evaluate which products or services satisfy predefined criteria and standards. For that reason, we think that our proposed model provides a useful and general framework to explain the impact that different gatekeeping institutions might have on the market within which they operate.

The approach we take in this paper can also be useful to the broader debate in management and organizational research about the effects of boundary spanning (Zuckerman 1999, Zuckerman, Kim, Ukanwa \& von Rittman 2003, Ruef \& Patterson 2009, Leahey, Beckman \& Stanko 2012, Ferguson \& Hasan 2013, Merluzzi \& Phillips 2015). That debate turns on the recognition that spanning boundaries often yields new information or resources to which others lack access and the simul- 
taneous recognition that spanning boundaries can make the spanner seem more confusing and illegitimate to external evaluators (Zuckerman 1999, Hannan, Pólos \& Carroll 2007). The debate, in other words, closely parallels the differing views of the relationship between knowledge recombination and innovation impact in patenting. Note that, in stressing differential selection as an outcome of institutional gatekeeping, we are highlighting how knowledge recombination induces what demographers call a morbidity/mortality tradeoff (Vaupel, Manton \& Stallard 1979). In this case, recombinant patents seem stronger than non-recombinants because the weaker recombinant applications are not approved. It is useful to highlight the generality of this mechanism, for two reasons. First, much of the debate about the effects of boundary spanning in organizational research stems from the observation that diversification is often penalized, yet we sometimes see "Renaissance men," objects or individuals who perform exceptionally well across categories (Zuckerman et al. 2003, Wu \& Dokko 2009, Ferguson \& Hasan 2013). The existence of many specialized actors and a handful of very successful diversified actors is exactly the distribution that we would expect a morbidity/mortality tradeoff to produce. This study is the first to explicitly model such a mechanism in an empirical setting where boundary spanning is recognized as more likely to produce occasional standout performers (Fleming 2001, Singh \& Fleming 2010). Second, while our main goal is to better understand the effects of knowledge recombination on innovation impact, our model does not rely on a mechanism that is specific to the inventive context. Differential selection can produce a variety of distributional outcomes, depending on the selection criteria.

In using a two-step model to unify these ideas, we build on Zuckerman's (1999) two-stage theory of candidate-audience interactions. We share the intuitions that inventions first have to be legitimated before they can have an impact; that various institutional gatekeepers impose a social structure on that legitimating process; and that spanning boundaries poses problems within that structure. We extend the approach to explore the benefits that boundary spanning can give to those who are approved. At the same time, we contribute to theories that stipulate performance benefits from boundary spanning, such as Burt's (1992) work on brokerage or the large body of work on knowledge recombination, by emphasizing the legitimation hurdles inherent in becoming a broker or combining knowledge.

Just as the benefits of brokerage are contingent (Reagans \& Zuckerman 2008), so too are the hurdles of legitimation (Zuckerman 1999, p. 1405). We have sketched scenarios (in figure 2) in 
which different combinations of approval hurdles and performance benefits apply. These different gatekeeping scenarios give us a succinct way to describe salient features of a given context. Patenting, we have argued, is a "type IV" scenario: one where more recombinant inventions face problems becoming approved but where there can be real impact benefits to spanning boundaries. Our treatment contrasts with most previous innovation research, which has implicitly treated patenting as a "type II" scenario, where no approval hurdles exist. This idea can be applied elsewhere: many of the studies looking at the penalties of boundary spanning (Hsu, Hannan \& Koçak 2009), which presume both approval hurdles and "producer-side" problems stemming from the principle of allocation, would be "type III" scenarios. ${ }^{5}$ By specifying a unique set of parameters that can be estimated for each such type, we suggest a way to explore empirically which conditions hold in different kinds of markets.

A main limitation of this study is that we have proposed that recombinant patent applications are less likely to be approved because of the greater organizational and cognitive burdens that they place on patent examiners, but we have only shown indirect evidence of this in the form of application review times. This is not the only mechanism that could produce our pattern of results. As we have discussed, prior work often assumes that the quality distribution of recombinant inventions is more heavily right-skewed than the quality distribution of non-recombinant inventions. This is the motivation for studying variance as well as mean effects in innovation studies. When modeling approval and impact jointly, such as we do here, a difference in the skewness of quality could produce sample selection, even if the same threshold were being applied to broad and narrow applications of the same quality. We have presented an alternative data-generating process to what most prior work has presumed; judging between them is a promising area for future research.

Though we lack direct information on the details through which differential selection plays out, the empirical fact of such selection here is clear: correcting for sample selection substantially reduces the estimated effects of knowledge recombination. Given the widespread interest in boundaryspanning processes among management researchers, in the domain of invention or elsewhere, we find the prospect of accounting for other types of performance through the mechanism of differential selection exciting. The question of whether it is better to conform to a set of expectations or strike

\footnotetext{
${ }^{5}$ It is harder to think of examples of "type I" scenarios in organizational research-perhaps because these most resemble simple commodity markets, which tend to be organizationally uninteresting.
} 
one's own path is a perennial one in management research. With the right data, this approach may help us to understand some of the other long-standing contradictory findings in our field. 


\section{A Appendix: Patent examination within the EPO}

We argue that the patent-approval process is an instance of institutional gatekeeping, in which ideas and technologies are recognized and given the imprimatur of innovation. We think that that process can systematically shape the population of inventions whose subsequent impact has been the focus of prior research. Here we detail the patent-granting process, as well as the ways such systematic behavior may appear.

\section{The patent-granting process}

Because we use European data, we focus here on the procedures of the EPO. We stress however that the EPO differs from the USPTO primarily in what it records. The patent-reviewing procedures of the USPTO are broadly comparable. The EPO subscribes to an internationally harmonized application and examination procedure for applicants seeking legal protection for their inventions under the European Patent Convention (EPC). When applying, applicants must specify the EPC member states in which they seek patent protection. In theory one can seek separate patent protection from each national office, but in practice applicants find it cheaper and faster to seek EPO protection if they plan to operate in multiple countries (Harhoff \& Reitzig 2004).

When an application is filed, the EPO designates a patent examiner to generate a "search report." The report's goal is to provide a comprehensive account of the "prior art," the body of existing public knowledge (mainly, prior patents, patent applications, and scientific publications) to which the invention relates. Thus, the search report both chronicles the existing knowledge on which the invention builds and delimits the scope beyond which it can make a claim of novelty and inventiveness. While in the United States the applicant is legally obliged to compile a list of prior art, in Europe the patent examiner generates the report (Meyer 2000, Michel \& Bettels 2001).

We put little theoretical weight here on whether the inventor or the examiner generates the list of prior art. Innovation research has never theorized that it is the list of citations, in and of itself, that determines how innovative an invention is. Rather, studies have treated citations to prior art as a reasonably accurate operationalization of the theoretical construct of knowledge recombination (Fleming 2001, Fleming \& Sorenson 2001, Rosenkopf \& Nerkar 2001). We emphasize this point because we want to distinguish between two very different scenarios in which greater breadth of citations could be associated with lower application-approval rates. In the first, citing more and broader prior work is basically a mistake that the applicant makes. By failing to specify where their invention's contribution lies, the applicant confuses the examiner and makes approval less likely. In this scenario, it is quite important whether the applicant or the examiner generates the list of prior art. But neither we nor prior work envision this scenario. In the second, citing broader prior work reflects something about the invention itself - that the invention draws upon and potentially makes contributions to different technology domains. Equally competent applicants and examiners would both cite the same prior art. Indeed, we think the EPO's procedure gives some advantage over the USPTO procedure, insofar as the inventor is unable to engage in strategic citation.

Therefore, when we say that a patent application that combines knowledge from multiple technology domains is more confusing for an examiner, we do not mean that the citations themselves are confusing. Rather, we presume that the citation pattern proxies for the invention, and it is making sense of that invention - parsing how it draws on and takes an inventive step beyond multiple bodies of knowledge - that is more difficult for an examiner than in the case of a more narrowly-focused invention. In short, the search report is important because the compilation of prior art within it tells us how much knowledge recombination is inherent in the invention. This in turn suggests both how impactful and how difficult to categorize the invention will be. 
About 18 months after the filing date, the EPO publishes its search report in the EPO Bulletin, along with the patent application. The applicant then has six months to request the examination of their application. If the applicant fails to request examination in this period, the examiner classifies the application as "deemed to be withdrawn," and the application process ends. Applicants can also explicitly withdraw applications. Both withdrawal outcomes are crucial because quite often they represent implicit rejections of the application. Implicit and explicit withdrawals typically occur when, in the "search opinion" portion of the search report, the examiner "outlines why the examiner believes that the application or invention does not meet the requirements of the EPC...[and] may suggest amendments to overcome the objections" (from the EPO's web site). The opinion informs the applicant whether a patent grant is unlikely and/or whether getting a grant would require changes to the patent's scope that would dwarf the revised patent's expected value (Lazaridis \& van Pottelsberghe de la Potterie 2007). It is after the search report and before examination that applicants must pay a substantial fee for the process to continue, so this decision is consequential.

If applicants do request examination of their application in the allotted time, the EPO then examines the invention to decide if it meets its stipulated three minimal criteria for patentability: novelty, inventiveness, and industrial applicability. This examination can have three different outcomes. First, the examiner may conclude that patent should be granted to the invention as specified in the application. Second, they may reject the application. Third, they may require changes. In the last case, negotiation then typically ensues between the examiner and the applicant on the exact terms of the necessary changes, at the end of which the patent may be rejected or granted. Once they are granted a patent, the inventors can then validate it with the national patent offices of the designated states for which patent protection was originally sought.

\section{Recombinant breadth and patent approval}

Given how many patent applications are deemed withdrawn-i.e., abandoned before a formal ruling on patentability - the search report is an important document. Patent research in multiple fields focuses on the search report because it is from its chronicling of prior art that citation data are constructed. We want to stress that the search report plays another function: it is a signal to the applicant of the likelihood that the EPO will grant patent protection to their invention (Lazaridis \& van Pottelsberghe de la Potterie 2007). It is through this process that an invention is recognized. And unlike the impact of a patent, which is determined by individual inventors often working in the same field, the approval of a patent application largely depends on gatekeeping by the patent examiners. Processes which shape their decisions shape the population of patents.

Innovation research typically argues that broader knowledge recombinations are associated with inventions that will have higher citation counts and greater technological and economic value. Yet before the patent has been granted, the same boundary spanning may create organizational and cognitive difficulties for the appraisal of the invention. As a result, broad patent applications may face higher approval hurdles than more narrowly focused ones. In practice, those hurdles are the problems that patent examiners face in compiling concise, accurate, and useful search reports when they try to synthesize information about a larger number of technological domains.

It is helpful to consider, even in a stylized example, the workflow of a patent examiner when a new application is filed. In the simplest case, an application that has a single technological class, the application will be sent to an examiner who specializes in that class. That examiner compiles a report based on their research and knowledge of the relevant prior art as well as their determination of the overlap and contribution that the application makes to its listed domain. The examiner writes up a search report detailing their findings. Based on the report, the applicant decides whether or not to proceed with examination. 
For an application that spans more technological classes, the process becomes more complicated. No one examiner is an expert in all technological classes, so teams may work on such reports. The members of such teams have differing technological expertise and may also differ in their estimation of the importance of the patent to the different technological domains (and vice versa). Because they differ in expertise, the examiners can differ in what they think must be revised in the application, and how. Compiling orthogonal or conflicting recommendations into a single search report is a non-trivial task. Such coordination among examiners poses an organizational hurdle to broad applications.

There are cognitive hurdles as well. Having a single examiner compile the search report for a broad application may remove the difficulty of coordinating among examiners, but it does not remove the need for that examiner to determine the novelty, inventive step, and possible infringements of an application that spans multiple technological classes and cites many diverse literatures. Indeed it is such cognitive limitations that encourage the division of labor in the examiners' office to begin with.

We emphasize that the patent examiner must decide whether an invention makes a useful and novel contribution relative to what has come before. We do so because it helps resolve a conceptual tension inherent in claiming that patent examiners may have difficulty evaluating broad patent applications. We do not think that patent examiners devalue broader applications simply because they are new or unfamiliar. Indeed we have bracketed how novel or typical such applications are in our main analyses. After all, it is the patent examiner's job to recognize and certify novelty and invention. Knowledge recombination can pose problems for examiners, not through the shock of the new, but through the effort required to commensurate different bodies of knowledge and to identify distinctive contributions in increasingly crowded thickets in the map of technology (Bessen 2003, Fleming \& Sorenson 2004). Agreement on whether an application is sufficiently inventive should be harder to achieve as the number of technology classes increases (Tan 2015).

The problems posed by these organizational and cognitive difficulties should result in search reports that are less favorable toward a broader application's being granted patent. Obviously, stronger applications will overcome such obstacles and receive patent protection regardless - but it is precisely this stricter selection which will tend to increase the mean quality of boundary-spanning inventions. 


\section{B Appendix: Exclusion using art-unit workload}

We fit two-stage models that first estimate the effects of recombinant breadth on a patent application's being granted and then the effects of breadth on citations that the patent receives. The difficulty with such models is that many features of an invention that predict its being granted patent (most notably, its quality) should also predict its being cited by future innovators. Including only such variables means relying on assumptions about the models' functional form to identify selection effects. This is an unacceptably strong assumption in the best of circumstances. We would prefer to include a variable or variables in the first stage whose effect on future citations happens only through the indirect channel of selection itself. That is, we need a variable that is correlated with application granting but is uncorrelated with forward citations.

In recent work with USPTO data, researchers have used fixed effects for patent examiners to provide exogenous variation. Patent examiners vary in stringency when evaluating patents, and the assignment of a particular application to a particular examiner is uncorrelated with observable measures of invention quality (Lemley \& Sampat 2012). As of this writing, though, the EPO refuses to release detailed information on patent examiners.

Rather than exploit idiosyncratic variation in approval likelihood by examiner, we exploit such variation by time. We leverage the fact that examiners' workloads, and the resulting amounts of time that they have to devote to each application, vary. This variation has nothing to do with the focal patent application. We know that evaluator behavior often shifts under the pressures of increased workloads (Simcoe \& Waguespack 2011, Boudreau, Guinan, Lakhani \& Riedl 2016), producing greater or lesser stringency depending on the context. And there is a first-order negative relationship in our data between the workloads of EPO art units receive and their approval rates. Thus art-unit workload has the potential to meet the exclusion restriction in our models.

However, several non-idiosyncratic trends must be removed from examiner workload for it to work as a plausible instrument. First, the number of patent applications received by most EPO art units has increased over time. Second, the workload varies systematically across art units, which reflects the uneven nature of advancement along the knowledge frontier as inventors exploit new technological opportunities. It is reasonable to presume that the EPO assigns staff to art units in proportion to their expected workloads.

We therefore develop a measure of idiosyncratic fluctuations in art-unit workloads by first constructing a panel of workloads by art unit-month and then purging it of systematic variation by time and art unit. Let $w_{j t}$ be the workload in art unit $j$ in month $t$. Here $t$ is a specific month, such as January 2000. Workload is highly right skew, so we take its natural log; figure B1 shows a histogram of the logged workload. We want to regress $\ln \left(w_{j t}\right)$ on a full suite of month, art-unit, and art-unit/year indicator variables. Because interacting art units with years would produce roughly 20,000 variables and because we are interested in removing the systematic variation and not in recovering the fixed effects themselves, we demean the observations by the group mean for their corresponding art-unit/year. We regress the de-meaned variable on the full suite of $615 t$ month dummies and $631 j$ art-unit dummies. We use robust standard errors in this regression to account for how the absolute variance in workload grows with the mean. This regression removes any timeseries variation as well as any systematic differences in workload across art units that may change over time. We calculate $\ln \left(\hat{w}_{j t}\right)$ and take the residual. We interpret this residual, $\ln \left(\dot{w}_{j t}\right)$, as the idiosyncratic art-unit workload in a given month, above or below what was suspected given the secular trend of applications arriving in that unit.

Figure B2 plots the residuals against the observed values for the monthly workload. The correlation between the two is less than .001. We are confident that the regression purges any systematic (and thus potentially endogenous) variation from this workload measure. 


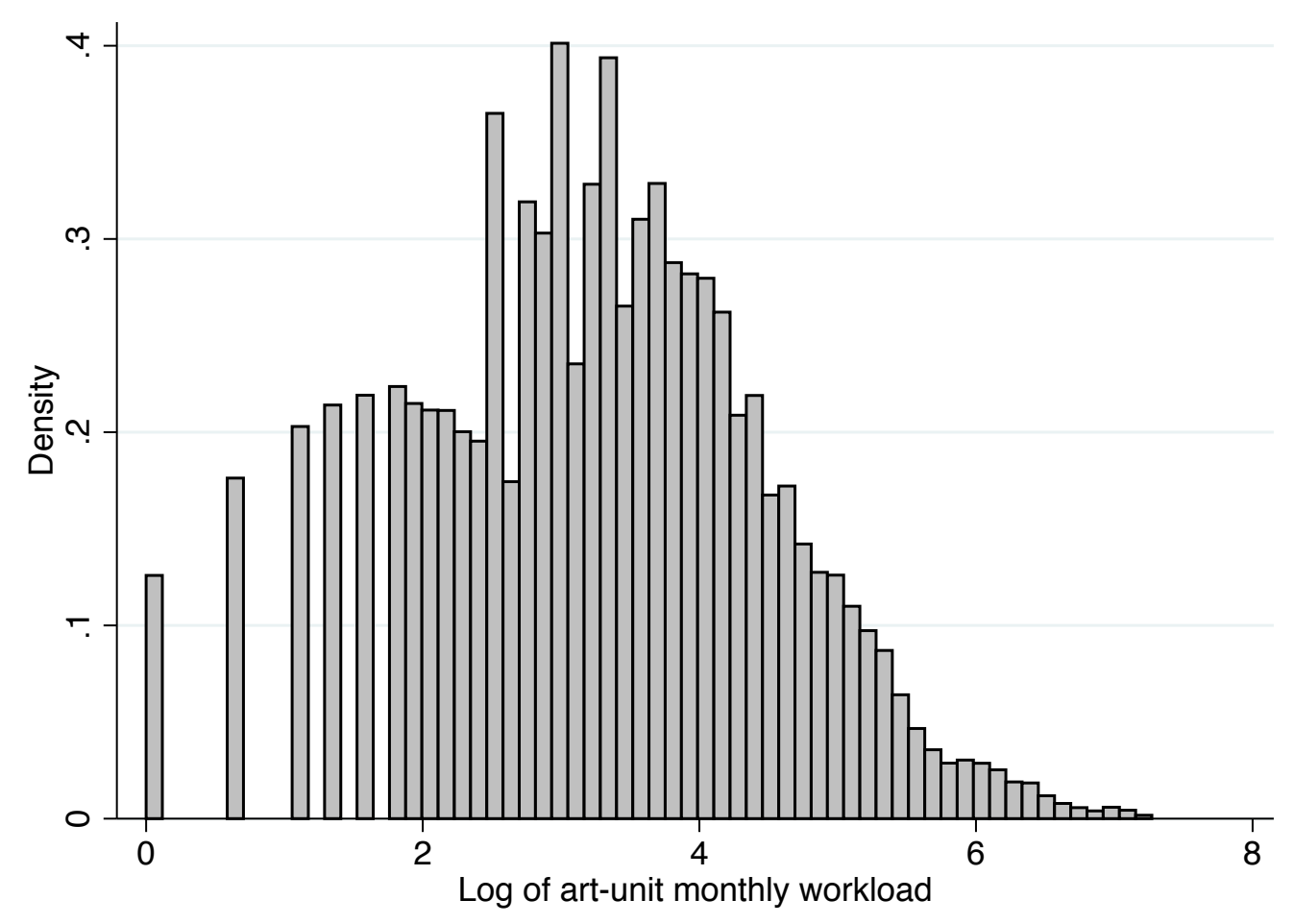

Figure B1: Distribution of the logged values of monthly art-unit workloads. See table 4 for details about the sample.

We next checked the correlation of this workload measure with the other model variables. Table B1 presents a balance test. To produce the coefficients in this table, we regressed each of the listed variables on art-unit workload, with the same sample of observations used in tables 4 and 5. Workload is significantly correlated with the probability of an application's being granted but not significantly correlated with other variables in the model. We also checked its correlation with variables in the citation stage. The closest to significance we see is with technical fertility, where $p<.1$. The idiosyncratic variation in art-unit workload among granted patents is not directly correlated with those patents' forward citation counts.

Finally, we ran a placebo test. Art-unit workload in the month an application is filed is correlated with the likelihood of that application's being granted patent, but one might reasonably argue that this measure is picking up something else if the workload in other months is also correlated with granting rates. We therefore estimated correlations between granting and $\ln \left(\dot{w}_{j, t-3}\right)$ through $\ln \left(\dot{w}_{j, t+3}\right)$. We present these in figure B3. There are significant correlations between workloads in the months immediately before and after an application is filed and granting rates. This surely reflects how work on specific applications can spill over from month to month, and how the art units can adjust to increased workloads with some lag. But the coefficients in $t-1$ and $t+1$ are much smaller than in $t$, and there is no significant correlation for the more temporally distant variables.

As with any instrumental variable, we cannot rule out the possibility that idiosyncratic changes in art-unit workloads are correlated with some unobserved variable. But its non-correlation with the observed variables puts some bounds on that concern. This, combined with its non-correlation with predicted workloads and the placebo test, gives us some confidence in using this measure to satisfy the exclusion restriction in the first stage of our models. 


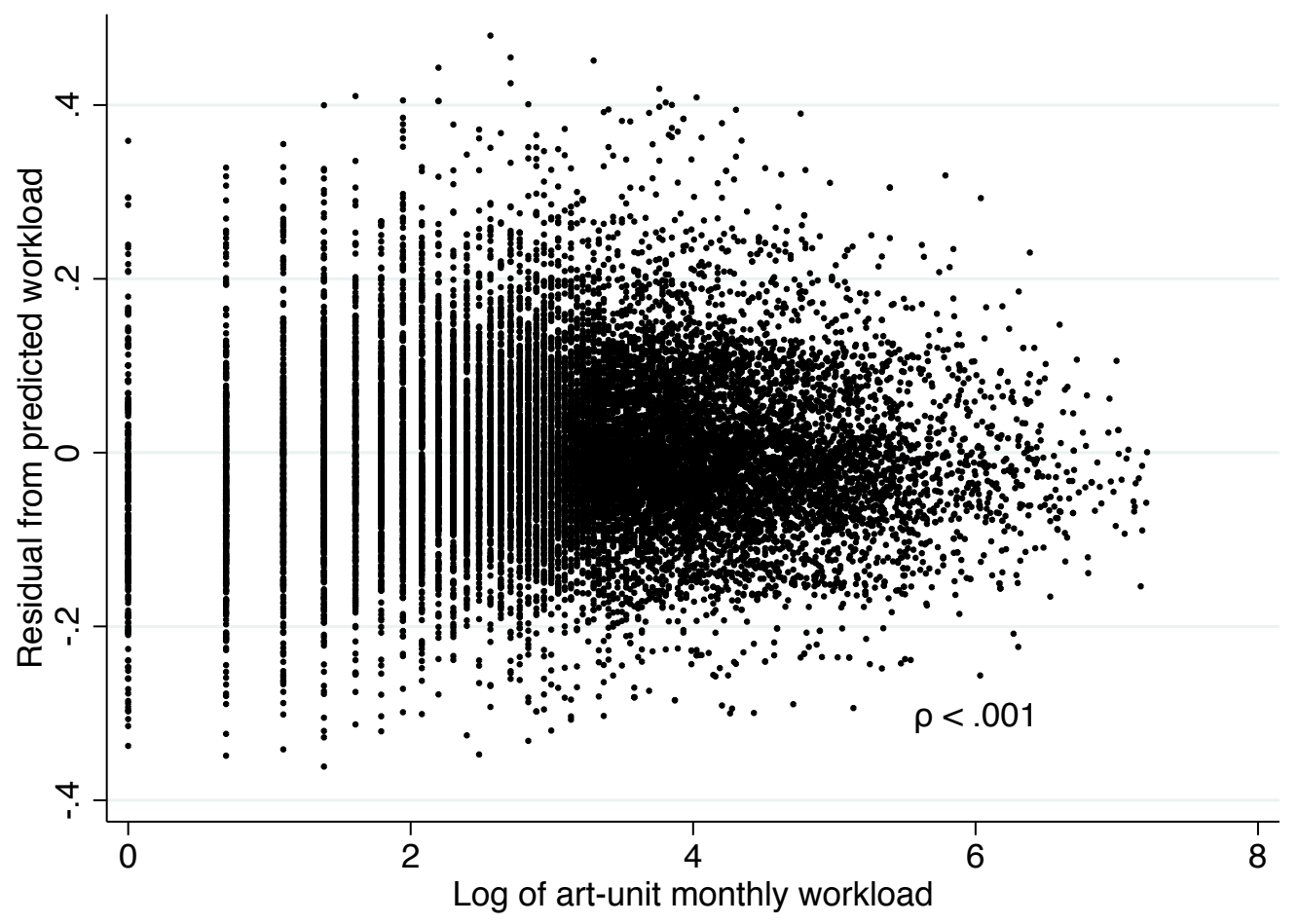

Figure B2: Scatterplot of observed (logged) monthly art-unit workloads against regression residuals. A random $1 \%$ sample of points are plotted here for clarity. We regressed $\ln \left(w_{j t}\right)=\alpha_{0}+\beta^{\prime} t+\gamma^{\prime} j+\delta^{\prime} j y$ where $t$ are unique month indicators (i.e., January 2000), $j$ are four-digit IPC art units, and $y$ are unique years. robust standard errors were calculated to account for the absolute variance of workloads growing with the mean. See table 4 for details about the sample. Gaps in the scatter plot result from logging the monthly workload counts; compare with figure B1. 
Table B1: Balance test of Art-unit workload against other variables used in models

\begin{tabular}{lc}
\hline \hline Patent-granting stage & $-0.031^{* *}$ \\
Application granted & $(0.008)$ \\
& -0.031 \\
Patent breadth & $(0.029)$ \\
& 0.023 \\
$\ln$ (Backward citation count) & $(0.023)$ \\
& -0.034 \\
$\ln$ (Inventor count) & $(0.021)$ \\
& -0.017 \\
$\ln$ (Technical fertility) & $(0.018)$ \\
& ---- \\
\hline Patent-citation stage ---- & -1.691 \\
Forward citation count & 0.921 \\
& -0.025 \\
Patent breadth & $(0.018)$ \\
& -0.007 \\
$\ln$ (Backward citation count) & $(0.013)$ \\
& -0.005 \\
$\ln$ (Avg. citation age) & $(0.004)$ \\
& -0.039 \\
$\ln$ (Inventor count) & $(0.025)$ \\
& $-0.141^{+}$ \\
$\ln$ (Technical fertility) & $(0.082)$ \\
\hline \hline
\end{tabular}

See tables 4 and 5 for details about the samples used in the two stages. Each coefficient represents the estimated effect of our art-unit workload measure on the listed variable in a bivariate regression with standard errors clustered by art units defined at the four-digit IPC level.

${ }^{+} p<0.1,{ }^{*} p<0.05,{ }^{* *} p<0.01$ 


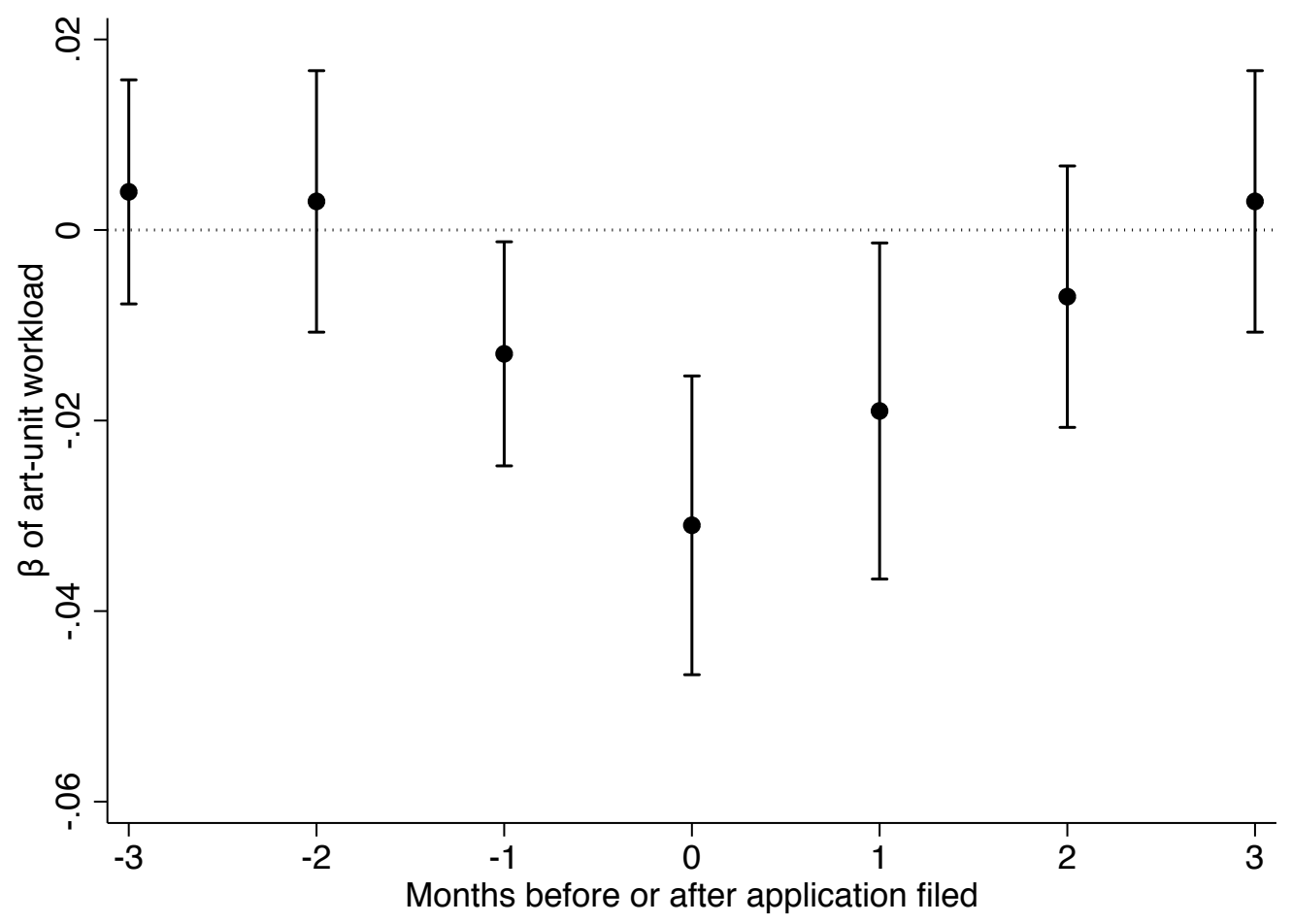

Figure B3: Robustness check of idiosyncratic art-unit workload's impact on patent-granting rates. See table 4 for details about the sample. Each point on the $x$-axis represents a bivariate regress of the probability of granting on workload, in which each observation has been assigned the value for the art unit's workload $x$ months before or after the application was actually filed. 


\section{Appendix: Citations to failed patent applications}

Within the European Patent Office, the examiners' mandate is to establish the novelty of a patent application, which requires identifying and citing all relevant public knowledge that constitutes prior art. Specifically, Article 54 of the European Patent Convention states the following:

1. An invention shall be considered to be new if it does not form part of the state of the art.

2. The state of the art shall be held to comprise everything made available to the public by means of a written or oral description, by use, or in any other way, before the date of filing of the European patent application.

3. Additionally, the content of European patent applications as filed, the dates of filing of which are prior to the date referred to in paragraph 2 and which were published on or after that date, shall be considered as comprised in the state of the art. [Emphasis added]

Because the EPO publishes patent applications before a granting decision is made (I.e., while the application is pending), the details of applications enter the stock of public knowledge before the application is granted. This can produce situations where an application is denied (perhaps the application is judged to have insufficient industrial applicability) yet where part of the invention is novel or otherwise relevant to subsequent work. When EPO examiners compile applications' search reports, they are required to acknowledge such relevant prior work, even if the application in which the work appeared was ultimately denied patent.

The European Patent Convention offers a legal rationale for this routine: If inventor $A$ applies for patent with an invention but is ultimately denied, and then inventor $B$ learns of advances in the state of knowledge from the published record of $A$ 's application and produces a new invention that receives patent, then inventor $A$ should still be able to develop inventions that build upon their own original ideas. If no citations to $A$ 's failed application were made in inventor $B$ 's patent, the evidence of $A$ 's inventive step would be separated from the patent and only visible in the application file. Hence the inclusion of references to $A$ 's failed application in $B$ 's patent's prior-art references.

More information can be found in reference to the European Patent Convention itself: http://www . epo.org/law-practice/legal-texts/html/epc/2016/e/ar54.html. 


\section{Appendix: Comparing recombinant breadth to similar mea- sures}

In their presentation of the measure of technological breadth, Gruber, Harhoff \& Hoisl (2013) argued and showed that it performs similarly to a simple Herfindahl index of the classes of a patent's backward citations. We constructed such a Herfindahl index and, as with the recombinantbreadth models, estimated its effects on the likelihood of application approval, built an inverse Mills ratio, and then estimated its effects on impact while controlling for selection. Such a Herfindahl is what Hall, Jaffe \& Trajtenberg (2001) referred to as the "originality" of a patent, and indeed our interpretation would be the same: original inventions are somewhat less likely to be approved but, once approved, have a greater impact. Tables D1 and D2 show similar patterns to what we find with our recombinant breadth measure. Finding comparable effects of institutional gatekeeping for this measure gives us some confidence that our main results are not simply an artifact of which measure of breadth we chose to use.

Table D1: Probit models predicting granting of patent application, using Herfindahl rather than recombinant breadth

\begin{tabular}{lccc}
\hline \hline & $(1)$ & $(2)$ & $(3)$ \\
\hline IPC Herfindhal & $-0.151^{* * *}$ & $-0.171^{* * *}$ & $-0.171^{* * *}$ \\
& $(0.028)$ & $(0.027)$ & $(0.027)$ \\
$\ln$ (Backward citation count) & & $0.033^{* * *}$ & $0.033^{* * *}$ \\
& & $(0.008)$ & $(0.008)$ \\
$\ln$ (Inventor count) & & $0.106^{* * *}$ & $0.106^{* * *}$ \\
& & $(0.006)$ & $(0.006)$ \\
$\ln$ (Tech. fertility) & & $-0.071^{* * *}$ & $-0.071^{* * *}$ \\
& & $(0.011)$ & $(0.011)$ \\
Art-unit workload & & & $-0.028^{* * *}$ \\
& & & $(0.008)$ \\
Filing-year F.E.s & $\mathrm{Y}$ & $\mathrm{Y}$ & $\mathrm{Y}$ \\
Constant & $0.770^{* * *}$ & $2.239^{* * *}$ & $2.233^{* * *}$ \\
& $(0.067)$ & $(0.257)$ & $(0.257)$ \\
\hline Observations & 844060 & 844060 & 844060 \\
Log-likelihood & -550434 & -548297 & -548286 \\
\hline \hline
\end{tabular}

See table 4 for details about the sample. Herfindahl index is calculated at the four-digit IPC level. Compare coefficients with table 4 in the main text. Standard errors, clustered by patent art units defined at the four-digit IPC level, are in parentheses.

${ }^{*} p<0.05,{ }^{* *} p<0.01,{ }^{* * *} p<0.001$ 
Table D2: QML Poisson models predicting forward-citation impact of granted patents, using Herfindahl rather than recombinant breadth

\begin{tabular}{lccc}
\hline \hline & $(1)$ & $(2)$ & $(3)$ \\
\hline IPC Herfindhal & $0.308^{* * *}$ & $0.124^{* * *}$ & $0.083^{* * *}$ \\
& $(0.009)$ & $(0.009)$ & $(0.010)$ \\
$\ln$ (Backward citation count) & & $0.143^{* * *}$ & $0.130^{* * *}$ \\
& & $(0.005)$ & $(0.005)$ \\
$\ln$ (Avg. citation age) & & $1.119^{* * *}$ & $1.122^{* * *}$ \\
& & $(0.025)$ & $(0.025)$ \\
$\ln$ (Inventor count) & & $0.158^{* * *}$ & $0.172^{* * *}$ \\
& & $(0.005)$ & $(0.005)$ \\
$\ln$ (Tech. fertility) & & $\left(0.142^{* * *}\right.$ & 0.032 \\
& & & $(0.018)$ \\
Inverse Mills ratio & & & $-0.420^{* * *}$ \\
& $\mathrm{Y}$ & $\mathrm{Y}$ & $\mathrm{Y}$ \\
Filing-year F.E.s & $\mathrm{Y}$ & $\mathrm{Y}$ & $\mathrm{Y}$ \\
Granting-year F.E.s & $2.554^{* * *}$ & $-10.743^{* * *}$ & $-7.124^{* * *}$ \\
Constant & $(0.005)$ & $(0.222)$ & $(0.601)$ \\
& 519475 & 519475 & 519475 \\
\hline Observations & -6872519 & -6584935 & -6584196 \\
Log-likelihood & & & \\
\hline \hline
\end{tabular}

See table 5 for details on the sample. Herfindahl index is calculated at the four-digit IPC level. Compare coefficients with table 5 in the main text.

Standard errors, clustered by patent art units defined at the four-digit IPC level, are in parentheses.

${ }^{*} p<0.05,{ }^{* *} p<0.01,{ }^{* * *} p<0.001$ 


\section{E Appendix: Investigating application review times}

If broader patent applications spend longer under review then broader applications will be overrepresented in the pending subset of our data. If many of these broad applications would ultimately be approved, then our estimate of the approval penalty on breadth in table 4 would be overstated.

We check against the possibility in two ways. First, we fit hazard models of approval on the data. These model results are shown in table E1. While broader patent applications are over-represented among pending records, the coefficients on recombinant breadth in Cox proportional-hazard models suggest that, if anything, these pending records are less likely to be approved at any given time than narrower pending applications are. Accounting for the greater likelihood that a broader application will be pending at any time of observation does not eliminate the negative coefficient on breadth. The approval penalty we find in our main analyses is not an artifact of ignoring pending applications.

Table E1: Cox proportional-hazard models predicting granting of patent application

\begin{tabular}{lccc}
\hline \hline & $(1)$ & $(2)$ & $(3)$ \\
\hline Patent breadth & $-0.269^{* * *}$ & $-0.161^{* * *}$ & $-0.161^{* * *}$ \\
& $(0.003)$ & $(0.004)$ & $(0.004)$ \\
$\ln$ (Backward citation count) & & $-0.101^{* * *}$ & $-0.101^{* * *}$ \\
& & $(0.002)$ & $(0.002)$ \\
$\ln$ (Inventor count) & & $-0.117^{* * *}$ & $-0.116^{* * *}$ \\
& & $(0.002)$ & $(0.002)$ \\
$\ln$ (Tech. fertility) & & $-0.157^{* * *}$ & $-0.156^{* * *}$ \\
& & $(0.001)$ & $(0.001)$ \\
Art-unit workload & & & $-0.119^{* * *}$ \\
& & & $(0.006)$ \\
Filing-year F.E.s & $\mathrm{Y}$ & $\mathrm{Y}$ & $\mathrm{Y}$ \\
\hline Observations & 1240377 & 1240377 & 1240377 \\
Log-likelihood & -6796611 & -6786600 & -6786390 \\
\hline \hline
\end{tabular}

See table 4 for details on the sample.

Standard errors in parentheses.

${ }^{*} p<0.05,{ }^{* *} p<0.01,{ }^{* * *} p<0.001$

Second, we estimate OLS models of the amount of time applications spend under review. Harhoff \& Wagner (2009) for example found that applications that cite more IPC classes spend longer in the examination process. We tested to see whether the same relationship holds when considering recombinant breadth. Table E2 presents OLS regressions of review time on breadth. Models 1 and 2 show that more breadth is associated with longer review times. We also examined the impact of radical innovations (as described in the main text, these are combinations of technology classes that have never been combined by previous patents) on review times. Model 1 shows that radical novelty is associated with shorter time under review, as we might predict. Model 2 tests an interaction between recombinant breadth and radical novelty; it shows that radical novelty can offset much of the increases in review time associated with breadth. This is consistent with our argument that the greatest hurdle in parsing boundary-spanning applications lie in determining the scope of the contribution of an invention that spans many domains (see appendix A). Approving an invention is quicker and easier when any examiner can see that a new bridge is being formed, regardless of the organizational and cognitive demands required to parse the rest of the application. 
Table E2: OLS models of review time for patent-granting process

\begin{tabular}{lcc}
\hline \hline & $(1)$ & $(2)$ \\
\hline Patent breadth & $229.208^{* * *}$ & $231.485^{* * *}$ \\
& $(38.166)$ & $(38.698)$ \\
Radical novelty & $-79.946^{*}$ & 49.814 \\
& $(36.912)$ & $(78.377)$ \\
Breadth $\times$ Novelty & & $-174.741^{*}$ \\
& & $(85.907)$ \\
$\ln ($ Backward citation count) & $48.650^{* *}$ & $48.631^{* *}$ \\
& $(15.876)$ & $(15.876)$ \\
$\ln$ (Inventor count) & $68.676^{* * *}$ & $68.636^{* * *}$ \\
& $(12.521)$ & $(12.523)$ \\
Filing-year F.E.s & $\mathrm{Y}$ & $\mathrm{Y}$ \\
Constant & $1292.461^{* * *}$ & $1293.289^{* * *}$ \\
& $(112.462)$ & $(112.379)$ \\
\hline Observations & 546593 & 546593 \\
$R^{2}$ & 0.13 & 0.13 \\
\hline \hline
\end{tabular}

Models are estimated on all closed cases of patents with non-missing data filed with the EPO between 1983 and 2007.

Standard errors, clustered by patent art units defined at the 4-digit IPC level, are in parentheses.

${ }^{*} p<0.05,{ }^{* *} p<0.01,{ }^{* * *} p<0.001$

We also think that review time is worth considering because it gives indirect evidence of the mechanisms that we have proposed are at work behind approval hurdles. If patent examiners interpret atypical combinations as a mark of novelty and inventiveness, they should approve an application faster if that application comprises unambiguously new combinations, like those we have flagged with our novelty variable. Furthermore, such unambiguous marks of novelty should be especially relevant when examiners face broad, boundary-spanning applications. We say this because, as we have argued, the greatest difficulties in parsing broad applications should lie in determining the scope of the contribution of an invention that bridges many domains. In other words, although examiners are generally less likely to identify the inventive step of broader applications, when such applications comprise an unambiguously novel combination then they can recognize that as something novel and inventive. 


\section{F Appendix: Additional comparison of recombinant breadth and typicality}

When we compare the effects of recombinant breadth and typicality in the same model, we must use a subset of the observations that we use in our main analysis. This is because, while breadth is defined (as zero) for applications that only include citations to a single four-digit IPC class, the Jaccard is only defined over applications that cite multiple classes. Thus we first reproduce (in table F1 and F2 our main analyses on the subset of observations where recombinant breadth is greater than zero.

Table F1: Probit models predicting granting of patent application (breadth $>0)$

\begin{tabular}{lccc}
\hline \hline & $(1)$ & $(2)$ & $(3)$ \\
\hline Patent breadth & $-0.452^{* * *}$ & $-0.441^{* * *}$ & $-0.441^{* * *}$ \\
& $(0.052)$ & $(0.048)$ & $(0.048)$ \\
$\ln$ (Backward citation count) & & 0.011 & 0.011 \\
& & $(0.007)$ & $(0.007)$ \\
$\ln$ (Inventor count) & & $0.101^{* * *}$ & $0.101^{* * *}$ \\
& & $(0.006)$ & $(0.006)$ \\
$\ln$ (Tech. fertility) & & $-0.084^{* * *}$ & $-0.084^{* * *}$ \\
& & $(0.010)$ & $(0.010)$ \\
Art-unit workload & & & $-0.032^{* * *}$ \\
& & & $(0.007)$ \\
Filing-year F.E.s & $\mathrm{Y}$ & $\mathrm{Y}$ & $\mathrm{Y}$ \\
Constant & $1.115^{* * *}$ & $2.946^{* * *}$ & $2.938^{* * *}$ \\
& $(0.085)$ & $(0.254)$ & $(0.254)$ \\
\hline Observations & 617997 & 617997 & 617997 \\
Log-likelihood & -404481 & -402831 & -402819 \\
\hline \hline
\end{tabular}

Models are estimated on the subset of patent applications with non-missing data filed at the EPO between 1983 and 2007, where recombinant breadth of the application's prior work is greater than zero.

Standard errors, clustered by patent art units defined at the four-digit IPC level, are in parentheses.

${ }^{*} p<0.05,{ }^{* *} p<0.01,{ }^{* * *} p<0.001$

One point that should be noted is that, on this subset of observations, when controlling for selection the effect of recombinant breadth on citation impact is not statistically different from zero. However, this seems to be due to weaker precision rather than a real effect. The absolute difference in the size of the coefficients between models 2 and 3 of table F2 is smaller than in table 5 , and the standard error on breadth in model 3 is considerably larger.

There is not no best practice for how to aggregate the dyadic Jaccard indices across all categories of an object into a single measure. In the main text we have used each application's minimum Jaccard. A similar case could be made for using the average Jaccard instead. We present results here with an average Jaccard as well. The substantive pattern of results is not changed. 
Table F2: QML Poisson models predicting forward-citation impact of granted patents (breadth $>0$ )

\begin{tabular}{|c|c|c|c|}
\hline & $(1)$ & $(2)$ & $(3)$ \\
\hline Patent breadth & $\begin{array}{c}0.189^{* * *} \\
(0.027)\end{array}$ & $\begin{array}{l}0.081^{* *} \\
(0.025)\end{array}$ & $\begin{array}{c}0.062 \\
(0.056)\end{array}$ \\
\hline $\ln$ (Backward citation count) & & $\begin{array}{c}0.158^{* * *} \\
(0.006)\end{array}$ & $\begin{array}{c}0.156^{* * *} \\
(0.008)\end{array}$ \\
\hline $\ln ($ Avg. citation age $)$ & & $\begin{array}{c}1.220^{* * *} \\
(0.031)\end{array}$ & $\begin{array}{c}1.220^{* * *} \\
(0.031)\end{array}$ \\
\hline $\ln ($ Inventor count) & & $\begin{array}{c}0.141^{* * *} \\
(0.006)\end{array}$ & $\begin{array}{c}0.141^{* * *} \\
(0.006)\end{array}$ \\
\hline $\ln$ (Tech. fertility) & & $\begin{array}{c}0.132^{* * *} \\
(0.003)\end{array}$ & $\begin{array}{c}0.129^{* * *} \\
(0.011)\end{array}$ \\
\hline Inverse Mills ratio & & & $\begin{array}{l}-0.044 \\
(0.130)\end{array}$ \\
\hline Constant & $\begin{array}{c}2.543^{* * *} \\
(0.023)\end{array}$ & $\begin{array}{c}-11.476^{* * *} \\
(0.277)\end{array}$ & $\begin{array}{c}-11.258^{* * *} \\
(0.689)\end{array}$ \\
\hline Observations & 375122 & 375122 & 375122 \\
\hline Log-likelihood & -5274047 & -5044364 & -5044362 \\
\hline
\end{tabular}

Models are estimated on the subset of patents with non-missing data filed with the EPO between 1983 and 2007 and granted by the EPO between 1984 and 2008 , where the recombinant breadth of the patent's prior work is greater than zero.

Standard errors, clustered by patent art units defined at the four-digit IPC level, are in parentheses.

${ }^{*} p<0.05,{ }^{* *} p<0.01,{ }^{* * *} p<0.001$ 
Table F3: Probit models predicting granting of patent application, using average rather than minimum Jaccard

\begin{tabular}{lcccc}
\hline \hline & $(1)$ & $(2)$ & $(3)$ & $(4)$ \\
\hline Average Jaccard & $-0.865^{* * *}$ & $-0.746^{* * *}$ & $-0.744^{* * *}$ & $-0.728^{* * *}$ \\
& $(0.098)$ & $(0.099)$ & $(0.099)$ & $(0.096)$ \\
Patent breadth & & & & $-0.072^{* * *}$ \\
& & & & $(0.009)$ \\
$\ln$ (Backward citation count) & & $0.020^{* * *}$ & $0.020^{* * *}$ & $0.027^{* * *}$ \\
& & $(0.005)$ & $(0.005)$ & $(0.005)$ \\
$\ln$ (Inventor count) & & $0.095^{* * *}$ & $0.095^{* * *}$ & $0.097^{* * *}$ \\
& & $(0.005)$ & $(0.005)$ & $(0.005)$ \\
$\ln$ (Tech. fertility) & & $-0.097^{* * *}$ & $-0.097^{* * *}$ & $-0.096^{* * *}$ \\
& & $(0.007)$ & $(0.007)$ & $(0.007)$ \\
Art-unit workload & & & $-0.024^{*}$ & $-0.024^{*}$ \\
& & & $(0.011)$ & $(0.011)$ \\
Filing-year F.E.s & $\mathrm{Y}$ & $\mathrm{Y}$ & $\mathrm{Y}$ & $\mathrm{Y}$ \\
Constant & $0.839^{* * *}$ & $3.106^{* * *}$ & $3.100^{* * *}$ & $3.104^{* * *}$ \\
& $(0.025)$ & $(0.183)$ & $(0.183)$ & $(0.182)$ \\
\hline Observations & 430375 & 430375 & 430375 & 430375 \\
Log-likelihood & -279316 & -278224 & -278220 & -278155 \\
\hline \hline
\end{tabular}

See table 4 for details on the sample. Models here are estimated on the subset where the application lists two or more IPC classes. The Jaccard is not defined for single-class cases - hence the smaller number of observations compared to table 4 .

Standard errors, clustered by patent art units defined at the four-digit IPC level, are in parentheses.

${ }^{*} p<0.05,{ }^{* *} p<0.01,{ }^{* * *} p<0.001$ 
Table F4: QML Poisson models predicting forward-citation impact of granted patents, using average rather than minimum Jaccard

\begin{tabular}{lccccc}
\hline \hline & $(1)$ & $(2)$ & $(3)$ & $(4)$ & $(5)$ \\
\hline Average Jaccard & $-0.462^{* * *}$ & $-1.280^{* * *}$ & $-1.334^{* * *}$ & $-1.290^{* * *}$ & $-1.029^{* * *}$ \\
& $(0.034)$ & $(0.039)$ & $(0.044)$ & $(0.039)$ & $(0.077)$ \\
Patent breadth & & & & $0.212^{* * *}$ & $0.040^{* * *}$ \\
& & & & $(0.043)$ & $(0.011)$ \\
$\ln$ (Backward citation count) & & $0.155^{* * *}$ & $0.149^{* * *}$ & $0.152^{* * *}$ & $0.170^{* * *}$ \\
& & $(0.007)$ & $(0.007)$ & $(0.007)$ & $(0.007)$ \\
$\ln$ (Avg. citation age) & & $1.165^{* * *}$ & $1.162^{* * *}$ & $1.161^{* * *}$ & $1.160^{* * *}$ \\
& & $(0.036)$ & $(0.036)$ & $(0.036)$ & $(0.036)$ \\
$\ln$ (Inventor count) & & $0.150^{* * *}$ & $0.150^{* * *}$ & $0.149^{* * *}$ & $0.149^{* * *}$ \\
& & $(0.007)$ & $(0.007)$ & $(0.007)$ & $(0.007)$ \\
$\ln$ (Tech. fertility) & & $0.174^{* * *}$ & $0.167^{* * *}$ & $0.174^{* * *}$ & $0.215^{* * *}$ \\
& & $(0.005)$ & $(0.005)$ & $(0.005)$ & $(0.011)$ \\
Inverse Mills ratio & & & $-0.075^{* *}$ & & $0.426^{* * *}$ \\
& & & $(0.027)$ & & $(0.105)$ \\
Filing-year F.E.s & $\mathrm{Y}$ & $\mathrm{Y}$ & $\mathrm{Y}$ & $\mathrm{Y}$ & $\mathrm{Y}$ \\
Granting-year F.E.s & $\mathrm{Y}$ & $\mathrm{Y}$ & $\mathrm{Y}$ & $\mathrm{Y}$ & $\mathrm{Y}$ \\
Constant & $1.647^{* * *}$ & $-13.802^{* * *}$ & $-13.368^{* * *}$ & $-13.781^{* * *}$ & $-16.143^{* * *}$ \\
& $(0.240)$ & $(0.412)$ & $(0.440)$ & $(0.412)$ & $(0.680)$ \\
\hline Observations & 266175 & 266175 & 266175 & 266175 & 266175 \\
Log-likelihood & -4094042 & -3914575 & -3914325 & -3914172 & -3913830 \\
\hline \hline
\end{tabular}

See table 5 for details on the sample. Models here are estimated on the subset of patents where the patent lists two or more IPC classes. The Jaccard is not defined for single-class cases - hence the smaller number of observations compared to table 5 .

Standard errors, clustered by patent art units defined at the four-digit IPC level, are in parentheses.

${ }^{*} p<0.05,{ }^{* *} p<0.01,{ }^{* * *} p<0.001$ 


\section{References}

Andrews, Kenneth T. \& Neal Caren. 2010. "Making the News: Movement Organizations, Media Attention, and the Public Agenda." American Sociological Review 75(6):841-866.

Azoulay, Pierre, Toby Stuart \& Yanbo Wang. 2013. "Matthew: Effect or Fable?" Management Science 60(1):92-109.

Bessen, James E. 2003. "Patent Thickets: Strategic Patenting of Complex Technologies." Available at SSRN: http://ssrn.com/abstract $=327760$.

Boudreau, Kevin J., Eva C. Guinan, Karim R. Lakhani \& Christoph Riedl. 2016. "Looking Across and Looking Beyond the Knowledge Frontier: Intellectual Distance, Novelty, and Resource Allocation in Science." Management Science . First published online at http://dx.doi.org/10.1287/mnsc.2015.2285.

Boudreau, Kevin J., Evan Guinan, Karim R. Lakhani \& Crhistoph Riedl. 2013. The Novelty Paradox and Bias for Normal Science: Evidence from Randomized Medical Grant Proposal Evaluations. Technical report Harvard Business School. Technology \& Operations Mgt. Unit Working Paper 13-053.

Burt, Ronald S. 1992. Structural Holes: The Social Structure of Competition. Cambridge, MA: Harvard University Press.

Burt, Ronald S. 2004. "Structural Holes and Good Ideas." American Journal of Sociology 110(2):349-399.

Carley, Michael, Deepak Hegde \& Alan Marco. 2015. "What is the Probability of Receiving a U.S. Patent?" Yale Journal of Law and Technology 17:203-223.

Carnabuci, Gianluca. 2014. "Knowledge Brokering." Forthcoming in the Palgrave Encyclopedia of Strategic Management (David Teece, editor).

Carnabuci, Gianluca \& Elisa Operti. 2013. "Where Do Firms' Recombinant Capabilities Come From? Intraorganizational Networks, Knowledge, and Firms' Ability to Innovate through Technological Recombination." Strategic Management Journal 34(13):1591-1613.

Carnabuci, Gianluca \& Elisa Operti. 2015. "Good for One but Bad for Most? How Intra-Organizational Networks Impact Innovative Performance at the Inventor and Firm Level." Working paper.

Carnabuci, Gianluca \& Jeroen Bruggeman. 2009. "Knowledge Specialization, Knowledge Brokerage and the Uneven Growth of Technology Domains." Social Forces 88(2):607-641.

Chaffin, Daniel Thomas, Ralph A. Heidl, Mukund Chari \& Roger Calantone. 2013. "The Role of Examiner Workload and Applicant Reputation in Intellectual Property Protection." Academy of Management Proceedings . doi: 10.5465/AMBPP.2013.219.

Clayman, Steven E. \& Ann Reisner. 1998. "Gatekeeping in Action: Editorial Conferences and Assessments of Newsworthiness." American Sociological Review 63(2):178-199.

Coffee Jr, John C. 2006. Gatekeepers: The Professions and Corporate Governance. Oxford: Oxford University Press.

Corredoira, Rafael A. \& Preeta M. Banerjee. 2014. "Measuring Patents' Influence on Technological Evolution: A Study of Knowledge Spanning as Driver of Inventive Activity." SSRN Working Paper.

Criscuolo, Paola, Linus Dahlander, Thorsten Grohsjean \& Ammon Salter. 2016. "Evaluating Novelty: The Role of Panels in the Selection of R\&D Projects." Academy of Management Journal . Published online in advance of print, 8 March 2016.

Dosi, Giovanni. 1982. "Technological Paradigms and Technological Trajectories: A Suggested Interpretation of the Determinants and Directionsof Technical Change." Research Policy 11(3):147-162.

Durand, Rodolphe \& Jean McGuire. 2005. "Legitimating agencies in the face of selection: The case of AACSB." Organization Studies 26(2):165-196. 
Ferguson, John-Paul \& Sharique Hasan. 2013. "Specialization and Career Dynamics: Evidence from the Indian Administrative Service." Administrative Science Quarterly 58(2):233-256.

Fleming, Lee. 2001. "Recombinant Uncertainty in Technological Search." Management Science 47(1):117132 .

Fleming, Lee \& Olav Sorenson. 2001. "Technology as a Complex Adaptive System: Evidence from Patent Data." Research Policy 30:1019-1039.

Fleming, Lee \& Olav Sorenson. 2004. "Science as a Map in Technological Search." Strategic Management Journal 25(8-9):909-928.

Fleming, Lee, Santiago Mingo \& David Chen. 2007. "Collaborative Brokerage, Generative Creativity, and Creative Success." Administrative Science Quarterly 52:443-475.

Foray, Dominique. 2006. Economics of Knowledge. Cambridge, MA: MIT Press.

Goossen, Martin C. 2014. "Internal Networks, External Networks, and Firm Innovation." Unpublished PhD Dissertation, HEC Paris.

Greene, William H. 1994. "Accounting for Excess Zeros and Sample Selection in Poisson and Negative Binomial Regression Models." Working Paper No. EC-94-10, Department of Economics, Stern School of Business, New York University.

Gruber, Marc, Dietmar Harhoff \& Karin Hoisl. 2013. "Knowledge Recombination across Technological Boundaries: Scientists vs. Engineers." Management Science 59(4):837-851.

Hall, Bronwyn H., Adam B. Jaffe \& Manuel Trajtenberg. 2001. The NBER Patent Citation Data File: Lessons, Insights, and Methodological Tools. Technical Report 8498 National Bureau of Economic Research.

Hannan, Michael T., Lásló Pólos \& Glenn R. Carroll. 2007. Logics of Organization Theory: Audiences, Codes, and Ecologies. Princeton, NJ: Princeton University Press.

Hargadon, Andrew B. 2002. "Brokering Knowledge: Linking Learning and Innovation." Research in Organizational Behavior 24:41-85.

Hargadon, Andrew \& Robert I. Sutton. 1997. "Technology Brokering and Innovation in a Product Development Firm." Administrative Science Quarterly 42(4):716-749.

Harhoff, Dietmar \& Markus Reitzig. 2004. "Determinants of Opposition Against EPO Patent GrantsThe Case of Biotechnology and Pharmaceuticals." International Journal of Industrial Organization 22(4):443-480.

Harhoff, Dietmar \& Stefan Wagner. 2009. "The Duration of Patent Examination at the European Patent Office." Management Science 55(12):1969-1984.

Hsu, David H. \& Kwanghui Lim. 2014. "Knowledge Brokering and Organizational Innovation: Founder Imprinting Effects." Organization Science 25(4):1134-1153.

Hsu, Greta \& Kimberly D. Elsbach. 2012. "Explaining Variation in Organizational Identity Categorization." Organization Science 24(4):996-1013.

Hsu, Greta, Michael T. Hannan \& Özgecan Koçak. 2009. "Multiple Category Memberships in Markets: An Integrative Theory and Two Empirical Tests." American Sociological Review 74:150-169.

Huang, Yi-Fen \& Chung-Jen Chen. 2010. "The Impact of Technological Diversity and Organizational Slack on Innovation." Technovation 30:420-428.

Jaffe, Adam B. \& Gaétan de Rassenfosse. 2016. "Patent Citation Data in Social Science Research: Overview and Best Practices." NBER Working Paper 21868.

Kaplan, Sarah \& Keyvan Vakili. 2015. "The Double-Edged Sword of Recombination in Breakthrough Innovation." Strategic Management Journal 36(10):1435-1457. 
Kim, Sang Kyun, Jonathan D. Arthurs, Arvin Sahaym \& John B. Cullen. 2013. "Search Behavior of the Diversified Firm: The Impact of Fit on Innovation." Strategic Management Journal 34:999-1009.

Kovacs, Balazs \& Michael T. Hannan. 2011. "Category Spanning, Distance and Appeal." Working paper.

Lazaridis, George \& Bruno van Pottelsberghe de la Potterie. 2007. "The Rigor of EPO's Patentability Criteria: An Insight Into the "Induced Withdrawals"." World Patent Information 29(4):317-326.

Leahey, Erin. 2006. "Gender Differences in Productivity: Research Specialization as a Missing Link." Gender and Society 20(6):754-780.

Leahey, Erin. 2007. "Not by Productivity Alone: How Visibility and Specialization Contribute to Academic Earnings." American Sociological Review 72(4):533-561.

Leahey, Erin, Christine M. Beckman \& Taryn Stanko. 2012. "The Impact of Interdisciplinarity on Scientists' Careers." Paper presented at the annual meeting of the American Sociological Association, Denver, CO.

Lemley, Mark A. \& Bhaven Sampat. 2008. "Is the Patent Office a Rubber Stamp?" Emory Law Journal 58:101-128.

Lemley, Mark A. \& Bhaven Sampat. 2012. "Examiner Characteristics and Patent Office Outcomes." Review of Economic Studies 94(3):817-827.

Lerner, Joshua. 1994. "The Importance of Patent Scope: An Empirical Analysis." RAND Journal of Economics 25(2):319-333.

McNeil, Kenneth \& Edmond Minihan. 1977. "Regulation of Medical Devices and Organizational Behavior in Hospitals." Administrative Science Quarterly 22(3):475-490.

Merluzzi, Jennifer \& Damon J. Phillips. 2015. "The Specialist Discount: Negative Returns for MBAs with Focused Profiles in Investment Banking." In press.

Meyer, Martin. 2000. "What Is So Special about Patent Citations? Differences between Scientific and Patent Citations." Scientometrics 49(1):93-123.

Michel, Jacques \& Bernd Bettels. 2001. "Patent Citation Analysis: A Closer Look at the Basic Input Data from Patent Search Reports." Scientometrics 51(1):185-201.

Miller, Douglas J., Michael T. Fern \& Laura B. Cardinal. 2007. "The Use of Knowledge for Technological Innovation within Diversified Firms." Academy of Management Journal 50(2):308-326.

Mokyr, Joel. 2002. The Gifts of Athena: Historical Origins of the Knowledge Economy. Princeton: Princeton University Press.

Mukherjee, Satyam, Brian Uzzi, Ben Jones \& Michael Stringer. 2016. "A New Method for Identifying Recombinations of Existing Knowledge Associated with High-Impact Innovation." Journal of Product Innovation Management 33(2):224-236.

Nerkar, Atul. 2003. "Old is Gold? The Value of Temporal Exploration in the Creation of New Knowledge." Management Science 49(2):211-229.

Polidoro, Francisco. 2013. "The Competitive Implications of Certifications: The Effects of Scientific and Regulatory Certifications on Entries into New Technical Fields." Academy of Management Journal 56(2):597-627.

Porter, Alan L. \& Frederick A. Rossini. 1985. "Peer review of interdisciplinary research proposals." Science, Technology, and Human Values pp. 33-38.

Quillen, Cecil D. \& Ogden H. Webster. 2006. "Continuing Patent Applications and Performance of the U.S. Patent and Trademark Office-Updated." Federal Circuit Bar Journal 15(4):635-677.

Reagans, Ray E. \& Ezra W. Zuckerman. 2008. "Why Knowledge Does Not Equal Power: The Network Redundancy Trade-Off." Industrial and Corporate Change 17(5):903-944. 
Rosenkopf, Lori \& Atul Nerkar. 2001. "Beyond Local Search: Boundary-spanning, Exploration, and Impact in the Optical Disk Industry." Strategic Management Journal 22(4):287-306.

Ruef, Martin \& Kelly Patterson. 2009. "Credit and Classification: The Impact of Industry Boundaries in 19th Century America." Administrative Science Quarterly 54:486-520.

Sampson, Rachelle C. 2007. "R\&D Alliances and Firm Performance: The Impact of Technological Diversity and Alliance Organization on Innovation." Academy of Management Journal 50(2):364-386.

Schilling, Melissa A. \& Elad Green. 2011. "Recombinant Search and Breakthrough Idead Generation: An Analysis of High Impact Papers in the Social Sciences." Research Policy 40:1321-1331.

Short, Jodi L., Michael W. Toffel \& Andrea R. Hugill. 2013. What shapes the gatekeepers? Evidence from global supply chain auditors. Technical report Harvard Business School. Technology \& Operations Mgt. Unit Working Paper 14-032.

Simcoe, Timothy S. \& Dave M. Waguespack. 2011. "Status, Quality, and Attention: What's in a (Missing) Name?" Management Science 57(2):274-290.

Sine, Wesley D., Robert J. David \& Hitoshi Mitsuhashi. 2007. "From Plan to Plant: Effects of Certificaton on Operational Start-up in the Emergent Independent Power Sector." Organization Science 18(4):578-594.

Singh, Jasjit \& Lee Fleming. 2010. "Lone Invetors as Sources of Breakthroughs: Myth or Reality?" Management Science 56(1):41-56.

Slager, Rieneke, Jean-Pascal Gond \& Jeremy Moon. 2012. "Standardization as Institutional Work: The Regulatory Power of a Responsible Investment Standard." Organization Studies 33(5-6):763-790.

Sorenson, Olav, Jan W. Rivkin \& Lee Fleming. 2006. "Complexity, Networks and Knowledge Flow." Research Policy 35:994-1017.

Sorenson, Olav \& Lee Fleming. 2004. "Science and the Diffusion of Knowledge." Research Policy 33(10):16151634.

Srivastava, Manish K. \& Devi R. Gnyawali. 2011. "When do Relational Resources Matter? Leveraging Portfolio Technological Resources for Breakthrough Innovation." Academy of Management Journal 54(4):797-810.

Sterzi, Valerio. 2013. "Patent Quality and Ownership: An Analysis of UK Faculty Patenting." Research Policy 42:564-576.

Tan, David. 2015. "To Fail in (Demonstrating) Originality: How Disconformity Obscures Distinctiveness." Working Paper, University of Washington Foster School of Business.

Tushman, Michael L. 1977. "Special Boundary Roles in the Innovation Process." Administrative Science Quarterly 22(4):587-605.

Tushman, Michael L. \& Thomas J. Scanlan. 1981. "Boundary Spanning Individuals: Their Role in Information Transfer and Their Antecedents." Academy of Management Journal 24(2):289-305.

Uzzi, Brian, Satyam Mukherjee, Michael Stringer \& Ben Jones. 2013. "Atypical Combinations and Scientific Impact." Science 342:468-472.

van Zeebroeck, Nicolas, Bruno van Pottelsberge de la Potterie \& Dominique Guellec. 2009. "Claiming More: The Increased Voluminosity of Patent Applications and its Determinants." Research Policy 38(6):10061020.

Vaupel, James W., Kenneth G. Manton \& Eric Stallard. 1979. "The Impact of Heterogeneity in Individual Frailty on the Dynamics of Mortality." Demography 16(3):439-454.

von Graevenitz, Georg, Stefan Wagner \& Dietmar Harhoff. 2011. "How to Measure Patent Thickets-A Novel Approach." Economics Letters 111(1):6-9.

Wang, Chunlei, Simon Rodan, Mark Fruin \& Xiaoyan Xu. 2014. "Knowledge Networks, Collaboration Networks, and Exploratory Innovation." Academy of Management Journal 57(2):484-514. 
Wang, Dan J. \& Sarah A. Soule. 2012. "Social Movement Organizational Collaboration: Networks of Learning and the Diffusion of Protest Tactics, 1960-1995." American Journal of Sociology 117(6):1674-1722.

Webster, Elizabeth, Paul H. Jensen \& Alfons Palangkaray. 2014. "Patent Examination Outcomes and the National Treatment Principle." RAND Journal of Economics 45(2):449-469.

Wegner, Harold. 2006. "The USPTO's 54\% Allowance Rate." IPFrontline, Dec. 30, http://www.ipfrontline.com/depts/article.asp?id=13796\&deptid $=5$.

Wooldridge, Jeffrey M. 1999. Quasi-Likelihood Methods for Count Data. In Handbook of Applied Econometrics, ed. M. Hashem Pesaran \& Peter Schmidt. Vol. II Blackwell chapter 8, pp. 352-406.

Wu, Geraldine \& Gina Dokko. 2009. "Typecasting Entrepreneurs: Boundary-Crossing and Firm Performance in High-Tech Ventures." Working paper.

Wuchty, Stefan, Benjamin F. Jones \& Brian Uzzi. 2007. "The Increasing Dominance of Teams in the Production of Knowledge." Science 316(5827):1036-1039.

Yayavaram, S. \& Gautam Ahuja. 2008. "Technological Search and Decomposability in Knowledge Structures: Impact on Invention Utility and Knowledge Base Malleability." Administrative Science Quarterly 53:333-362.

Zuckerman, Ezra W. 1999. "The Categorical Imperative: Securities Analysts and the Illegitimacy Discount." American Journal of Sociology 104(5):1398-1438.

Zuckerman, Ezra W. 2003. "Bringing (Crude) Functionalism Back In." Essay Prepared for Spring 2003 issue of "Accounts: A Newsletter of Economic Sociology".

Zuckerman, Ezra W. 2004. "Structural Incoherence and Stock Market Activity." American Sociological Review 69(3):405-432.

Zuckerman, Ezra W., Tai-Young Kim, Kalinda Ukanwa \& James von Rittman. 2003. "Robust Identities or Non-Entities? Typecasting in the Feature-Film Labor Market." American Journal of Sociology 108(5):1018-1074. 